\title{
Cloud-Spacing Effects upon Entrainment and Rainfall along a Convective Line
}

\author{
DANIEL H. MOSER ${ }^{\mathrm{a}}$ AND SONIA LASHER-TRAPP \\ Department of Atmospheric Sciences, University of Illinois at Urbana-Champaign, Urbana, Illinois
}

(Manuscript received 26 December 2017, in final form 26 May 2018)

\begin{abstract}
Cumulus clouds modify their immediate surroundings by detraining their warm, humid updrafts. When clouds are closely spaced, this conditioning of the local environment may alter the properties of the air entrained by neighboring clouds and slow their dilution. This effect has not been quantified, nor has its importance been determined for influencing the amount of convective rainfall from a system of neighboring clouds. Here, a series of idealized numerical simulations, which are based on an observed line of precipitating cumulus congestus clouds, is performed using increasingly smaller cloud spacing to investigate how cloud proximity may alter entrainment, cloud development, and convective rainfall. For clouds of radius $R$, which is approximately $1 \mathrm{~km}$ in these simulations, distances between updraft centers from $4 R$ through $9 R$ are tested. Over this range, the initial clouds all exhibit negligible differences in the directly calculated entrainment rates and in the thermodynamic characteristics of the entrained air. Instead, for cloud separation distances of less than $6 R$, the subcloud inflow is increasingly disturbed, limiting initial cloud depths and slowing updraft speeds and precipitation onset. Ultimately, however, these same cases produce a new generation of clouds that are stronger and produce more rainfall than for all other cases. The smaller cloud separation distance allows precipitation outflows from the initial clouds to meet and force new, stronger cloud updrafts. For this second generation of clouds, their entrained air is slightly more humid, but the stronger updrafts and ingestion of residual ice and precipitation from earlier clouds appear to be most important for enhancing their rainfall.
\end{abstract}

\section{Introduction}

Advances in computational power over the past few decades have allowed numerical weather prediction models to simulate convective systems with greater detail and accuracy. Despite these advances, quantitative precipitation forecasts still suffer poor skill (e.g., Fritsch and Carbone 2004), especially during the warm season where precipitation is frequently driven by smaller-scale convection (Barthold et al. 2015). Partially responsible for this problem is insufficient grid spacing to resolve the important features of convective cumulus clouds, as well as uncertainties in the rates at which microphysical processes occur. The problem is especially difficult in mixed-phase convection where interactions between warm-rain and ice-phase processes, which can be modified by entrainment, must be considered. These challenges

\footnotetext{
${ }^{\text {a }}$ Current affiliation: Lyda Hill Department of Bioinformatics, University of Texas Southwestern Medical Center, Dallas, Texas.
}

Corresponding author: Daniel H. Moser, daniel.moser@ utsouthwestern.edu inspired the Convective Precipitation Experiment (COPE) held in southwestern England in the summer of 2013 (Leon et al. 2016).

It is well established that convective development and rainfall are strongly related to cumulus entrainment. The mixing of the relatively cool, dry environmental air into the clouds gradually weakens their buoyancy and often limits their tops to well below the equilibrium level of undiluted parcels. Entrainment also removes large amounts of liquid water by evaporation (e.g., Stommel 1947; Warner 1955; Jonas and Mason 1982; Blyth et al. 2005), slows the rates of collision-coalescence and riming processes (e.g., Blyth 1993), and by extension reduces the overall amount of rainfall (e.g., Kessler 1969; Lasher-Trapp et al. 2001; Wang et al. 2007).

Some mechanisms may limit the magnitude of cloud dilution resulting from entrainment. A recent focus has been how the locally entrained air may differ substantially from the unperturbed environmental air farther from the clouds. New methods of directly calculating entrainment in cloud-resolving models have shown the entrained air is often moistened by detrained air that is recycled inward, slowing dilution (Romps and Kuang 2010; 
Dawe and Austin 2011a; Yeo and Romps 2013; Hannah 2017). Moser and Lasher-Trapp (2017) showed how successive thermals could entrain air substantially more humid than the environment when they ascended through the shed wakes of preceding thermals, minimizing dilution of the high liquid water content core, even during periods of strong entrainment, enhancing graupel and rain production.

While some insight has been gained by careful examination of the locally entrained air into an individual cloud, there is little understanding of how locally entrained air is modified by a population of clouds. Numerous studies have examined the effects of detrainment of a cloud ensemble upon the larger-scale environment, with the objective of improving parameterized feedbacks (e.g., Randall and Huffman 1982; de Rooy and Siebesma 2010; Dawe and Austin 2013, and others). However, very few studies have examined the effects of detrained air on individual clouds. Aircraft observations of isolated cumulus clouds have shown humidity enhancements around their edges called "humidity halos" (Perry and Hobbs 1996; Lu et al. 2003; Laird 2005; Twohy et al. 2009; Rauber et al. 2013). The spacing between clouds is often assumed to be important for entrainment; that is, closer spaced clouds may entrain locally moistened air, limiting their dilution, increasing their depths, and producing more rainfall, for example, the "near environment" hypothesis (Böing et al. 2012). Studies directly quantifying the extent of this moistening effect are lacking, however.

Complicating the quantification of any potential modification to entrainment by cloud spacing is the concurrent influence on cloud dynamical interactions. A simulation of neighboring warm bubbles by Kogan and Shapiro (1996) suggested a mutual interference of the organized inflow of subcloud air into their updrafts, limiting their development and rainfall prior to merging but deepening the convection after merging. Observations of cloud mergers led Simpson et al. (1980) to postulate that interacting outflows of two neighboring, precipitating clouds resulted in new, vigorous convection that bridged the two older clouds. Feng et al. (2015) concluded that the intersection of outflows reduced cloud separation, creating cloud clusters and self-organized convection, and qualitatively argued that the clouds would "shield" each other from the entrainment of dry air. Glenn and Krueger (2017) contended that the merged updrafts have a lower perimeterto-area ratio and thus are less susceptible to dilution by entrainment. Overall, both mechanisms link interactions with neighboring clouds to mitigate entrainment, and require more investigation.

The importance of modified entrainment and/or cloud dynamical interactions to the microphysical processes leading to precipitation is also of interest. Cores of high liquid water content (LWC) could potentially be maintained longer by the entrainment of moistened air and may lead to a more efficient warm-rain process lower in the cloud and/or enhanced riming above the melting layer (e.g., Cooper and Lawson 1984; Blyth and Latham 1993). Secondary ice production via the Hallett-Mossop process (Hallett and Mossop 1974) has also been shown to be highly sensitive to the amount of supercooled liquid water present (e.g., Blyth and Latham 1997). It requires graupel riming supercooled cloud droplets larger than $25 \mu \mathrm{m}$, in air temperatures between $-3^{\circ}$ and $-8^{\circ} \mathrm{C}$, and results in the ejection of small splinters as the droplets freeze (Mossop and Hallett 1974), potentially feeding back into the production of more graupel and ultimately more rain.

During the COPE field campaign, observations of a quasi-stationary, tightly packed line of precipitating cumulus clouds on 3 August 2013 were collected in situ by multiple aircraft, and remotely by airborne and ground-based radars. Cloud tops ranged in height from 4 to $6 \mathrm{~km}$ MSL in a weakly sheared environment $\left(\approx 1.4 \times 10^{-3} \mathrm{~s}^{-1}\right)$. Renewed cloud development through multiple thermals was observed throughout the line (Leon et al. 2016). Radar echo maxima up to $60 \mathrm{dBZ}$ were detected by the X-band radar, along with high differential reflectivity indicative of large raindrops carried above the melting level in the updrafts (Plummer et al. 2018). Aircraft measurements of ice exceeding $100 \mu \mathrm{m}$ in diameter sometimes surpassed several hundred per liter above the $-8^{\circ} \mathrm{C}$ isotherm, consistent with an active Hallett-Mossop process (Taylor et al. 2016; Jackson et al. 2018, manuscript submitted to Atmos. Chem. Phys. Discuss.). Clouds with tops below the $-10^{\circ} \mathrm{C}$ level had an active warm-rain process, before transitioning to mainly ice processes for those clouds that grew deeper (Taylor et al. 2016; Jackson et al. 2018, manuscript submitted to Atmos. Chem. Phys. Discuss.). Simulations by Lasher-Trapp et al. (2018, manuscript submitted to J. Appl. Meteor. Climatol.) corroborated the influence of the Hallett-Mossop process on ice concentrations for the 3 August clouds with tops above $5 \mathrm{~km}\left(-15^{\circ} \mathrm{C}\right)$. They concluded that the dominant microphysical pathway to rainfall was the freezing of supercooled raindrops to produce large ice particles, growing further by riming like graupel before melting and falling to the ground as rain. While these studies have illuminated the potential relative importance of various microphysical processes to the convective precipitation on 3 August, the influence of the closely spaced clouds upon entrainment, cloud development, and rainfall has yet to be examined.

The objective of this study is to understand and quantify how clouds developing in close proximity, as 
part of a linearly organized population, might differ dynamically and microphysically from those that develop in relative isolation because of entrainment or other effects. Idealized numerical simulations based upon the COPE observations of the precipitating convection on 3 August 2013 are employed for

1) comparing entrainment rates and the properties of entrained air for clouds developing closer together within a line as compared with those spaced farther apart,

2) examining the sensitivity of overall cloud development (maximum height, vertical mass flux) to the distance between neighboring clouds,

3) analyzing differences in microphysical processes resulting from potential modifications to entrainment or other effects of neighboring clouds, and

4) evaluating the combined effects upon surface rainfall.

\section{Methods}

\section{a. Model description}

Cloud Model 1 (CM1; Bryan and Fritsch 2002) is a $3 \mathrm{D}$, nonhydrostatic model that integrates the quasicompressible set of the Navier-Stokes equations forward in time using a third-order Runge-Kutta scheme. Subgrid-scale turbulence is parameterized by a 1.5 -order turbulence closure scheme. Open (radiative) boundary conditions were used for the horizontal boundaries of the domain, with a free-slip lower boundary condition, and a Rayleigh damping layer within the top $1.5 \mathrm{~km}$ of the domain. Several microphysics parameterizations are available in the model; the double-moment NSSL microphysics scheme (Mansell et al. 2010), which predicts the mass and number concentration of cloud water, cloud ice, rain, graupel, hail, and aggregates, was chosen for this study. The NSSL scheme includes the warm-rain parameterization of Ziegler (1985), primary ice nucleation and contact freezing from Meyers et al. (1992), HallettMossop secondary ice production from Cotton et al. (1986; second formulation based on cloud droplet size), and immersion freezing of raindrops by Bigg (1953).

\section{b. Simulation setup}

The base state for the model was initialized from a sounding released at 1000 UTC 3 August 2013 (Fig. 1) in the vicinity of the convective line that would form later. The equilibrium level of the sounding was $\sim 5 \mathrm{~km}$ $\left(-16^{\circ} \mathrm{C}\right)$, with the lifted condensation level (LCL) located near $0.7 \mathrm{~km}\left(10^{\circ} \mathrm{C}\right)$ AGL. The wind shear over this depth was only $6 \mathrm{~m} \mathrm{~s}^{-1}$, and the winds were approximately unidirectional from the southwest. It is

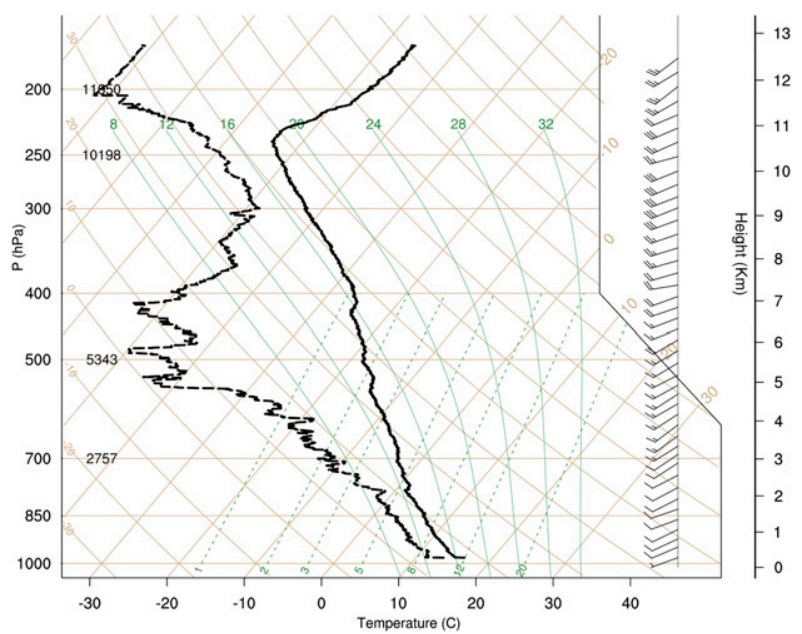

FIG. 1. An atmospheric sounding sampled near the line of cumulus congestus clouds over southwestern England at 1000 UTC 3 Aug 2013 and used for initializing the base state of the model.

more convenient for the line of clouds to develop parallel to the $x$ axis, so the winds were rotated clockwise to westerly in the model to allow for easier analysis of the simulation results. This is equivalent to rotating the $x$ axis counterclockwise so that it is parallel to the mean wind vector.

To mimic the effects of solar heating and the convergence of two sea breezes that produced the convective line on 3 August, five identical Gaussianshaped sensible heat fluxes (Klaassen and Clark 1985; Carpenter et al. 1998; Moser and Lasher-Trapp 2017) were applied at the surface to force five separate clouds. The 3D heat flux function $H$ is described, following the same notation as Carpenter et al. (1998), in the equation below:

$$
\begin{aligned}
H(x, y, z)= & \left\{H_{0}+H_{G} \exp \left[-\frac{\left(x-x_{0}\right)^{2}+\left(y-y_{0}\right)^{2}}{\sigma^{2}}\right]\right\} \\
& \times \exp \left(-\frac{z}{\alpha}\right)
\end{aligned}
$$

where $H_{0}$ and $H_{G}$ are, respectively, the magnitude of the surface heating over the entire domain at the surface, and the maximum magnitude of the five Gaussianshaped heat fluxes at their centers. The magnitudes of $H_{0}$ and $H_{G}$ increased linearly in time from zero to their maximum values at $30 \mathrm{~min}$ and then held constant until the end of the simulations at $150 \mathrm{~min}$. Each of the Gaussian heat fluxes were positioned at a specified $x_{0}$ and $y_{0}$, where $x, y$, and $z$ denote the coordinate axes on the Cartesian model grid. The value of $y_{0}$ was set to the center of the domain $(7.2 \mathrm{~km})$ for all fluxes in all simulations, while the values of $x_{0}$ changed for each of the 


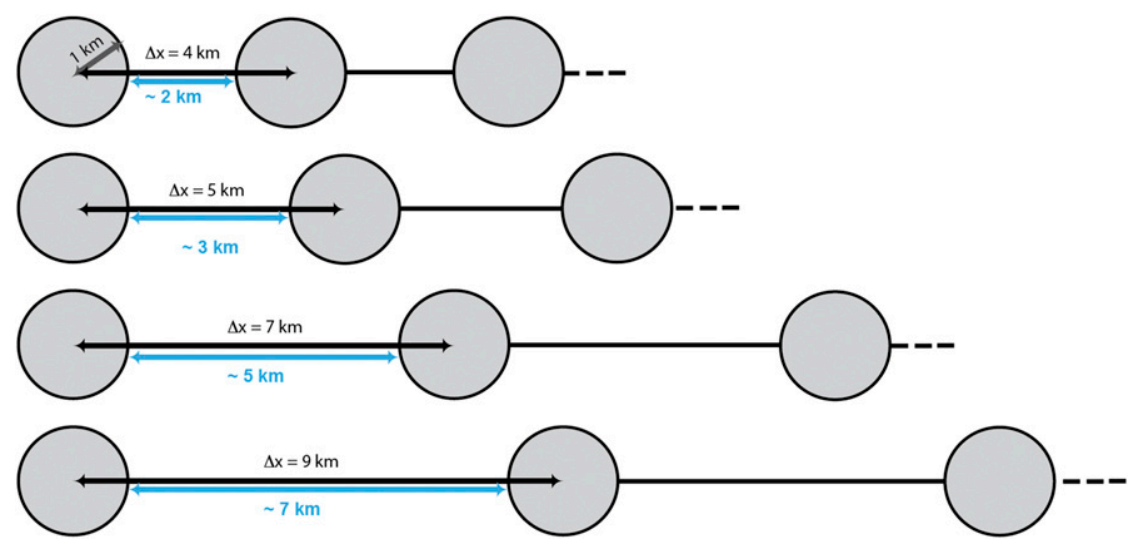

FIG. 2. Sample schematic of the cloud separation distances (black arrows; measured between surface heat flux maxima) for the $4 \mathrm{KM}, 5 \mathrm{KM}, 7 \mathrm{KM}$, and 9KM simulations, all using a cloud updraft radius of $R=1 \mathrm{~km}$. For each simulation, five clouds are initiated along the line, but only the first three are shown here for brevity. Blue arrows and labels denote approximate distances between cloud edges, for reference.

five Gaussian heat fluxes, spacing their centers evenly apart by $4,5,5.5,6,7,8$, or $9 \mathrm{~km}$. These runs are hereinafter referred to as $4 \mathrm{KM},{ }^{1} 5 \mathrm{KM}, 5.5 \mathrm{KM}, 6 \mathrm{KM}, 7 \mathrm{KM}$, $8 \mathrm{KM}$, and 9KM. The magnitudes of $H_{0}$ and $H_{G}$ were 150 and $450 \mathrm{~W} \mathrm{~m}^{-2}$, respectively. The $H_{G}$ decays with distance from each center as a function of the standard deviation $\sigma$, set to $2250 \mathrm{~m}$ for all runs, except for two modified 5KM runs in which $\sigma$ was decreased to $2000 \mathrm{~m}$ (labeled "narrow") or increased to $2500 \mathrm{~m}$ (labeled "wide"). The vast majority of the surface heating occurred within 1 standard deviation of each surface heat flux maximum, resulting in updraft radii of approximately $1 \mathrm{~km}$, comparable to those observed, and being slightly greater or less when the prescribed Gaussian shape was widened or narrowed. Thus, the corresponding distance between neighboring cloud edges is approximately $2 \mathrm{~km}$ less than the distance between their centers (see the schematic in Fig. 2). The Gaussian heating functions decay with height along an $e$-folding distance $\alpha$, set to $350 \mathrm{~m}$ for all simulations, so that heating decreased to $10 \%$ of its maximum value at the height of the cloud bases.

Estimates of distances between observed cloud centers along the convective line on 3 August, using three different radars from COPE, are shown in Fig. 3. The distances were computed by assuming precipitation from each cloud fell near the updraft (because of the

\footnotetext{
${ }^{1}$ When the clouds' centers were spaced closer than $4 \mathrm{~km}$, they often merged with a neighbor. Although this merging is not the focus of this work, some studies of this process include Simpson et al. (1980), Turpeinen and Yau (1981), Tao and Simpson (1989), Kogan and Shapiro (1996), Stalker and Knupp (2003), Krauss et al. (2012), and Glenn and Krueger (2017).
}

weak vertical wind shear on this day) and thus by using distances between reflectivity or radar-derived rain-rate maxima. The coarser resolution of the U.K. operational radar, as well as the use of maxima from its diagnosed rain rates that contained less detail, biased its estimates toward higher values. From the more detailed radar data, the Gaussian heating functions spaced $5 \mathrm{~km}$ apart are thought to best represent the real conditions on 3 August.

The domain size varied depending upon the spacing of the Gaussian heat maxima along the line for each simulation. The domain was always 14.4 and $8.25 \mathrm{~km}$ in the $y$ and $z$ directions, respectively. The length of the domain in the $x$ direction was extended to accommodate the larger distances between surface heat fluxes, ranging from $32 \mathrm{~km}$ in run $4 \mathrm{KM}$ to $52 \mathrm{~km}$ in run

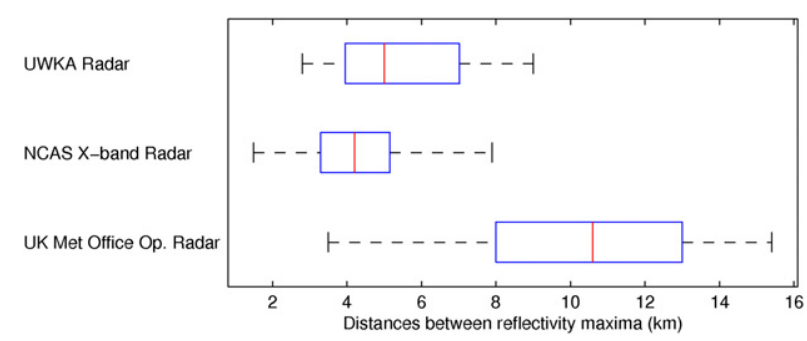

FIG. 3. Manually estimated distances between centers of adjacent cells along the convergence line sampled by the University of Wyoming King Air cloud radar (top plot), National Centre for Atmospheric Science (NCAS) X-band ground-based radar (middle plot), and Met Office operational radar (bottom plot) from 1200 to 1430 UTC 3 Aug 2013. The boxes enclose the 25th and 75th percentiles, with the interior red line showing the 50th percentile, and vertical black lines denote 2.7 standard deviations from the mean distance. 
9KM. A uniform grid spacing of $50 \mathrm{~m}$ was used in all simulations with a time step of $0.25 \mathrm{~s}$. The environmental winds throughout the domain are reduced by $8.5 \mathrm{~m} \mathrm{~s}^{-1}$ to keep the clouds over their respective zones of forcing, to emulate continued forcing over a persistent convergence line, and to prevent them from being advected out of the domain.

\section{c. Entrainment and detrainment calculations}

Entrainment and detrainment are defined as the mass flux into and out of a cloud core boundary following Siebesma (1998). Dawe and Austin (2011b) showed these fluxes can be directly calculated from the velocity and scalar fields for an Arakawa $\mathrm{C}$ grid cell by

$$
\begin{aligned}
E-D= & \rho_{(k)} \frac{d V_{(i, j, k)}}{d t}+\rho_{(k)} u_{(i+1, j, k)} W_{x(i+1, j, k)}-\rho_{(k)} u_{(i, j, k)} W_{x(i, j, k)}+\rho_{(k)} v_{(i, j+1, k)} W_{y(i, j+1, k)}-\rho_{(k)} v_{(i, j, k)} W_{y(i, j, k)} \\
& +0.5\left[\rho_{(k)}+\rho_{(k+1)}\right] w_{(i, j, k+1)} W_{z(i, j, k+1)}-0.5\left[\rho_{(k)}+\rho_{(k-1)}\right] w_{(i, j, k-1)} W_{z(i, j, k-1)},
\end{aligned}
$$

where $\rho$ is the moist air density $\left(\mathrm{kg} \mathrm{m}^{-3}\right) ; V$ is the (often partial) volume of the grid cell containing the cloud core; $u, v$, and $w$ are the velocity components of the flow $\left(\mathrm{m} \mathrm{s}^{-1}\right)$; and $W$ is the surface area of the cloud core $\left(\mathrm{m}^{2}\right)$ contained in the grid cell. A net positive value of (2) is considered entrainment, while a net negative value is considered detrainment, that is, a single grid cell is only allowed to entrain or detrain at any one time step. Following Dawe and Austin (2011b), the subgrid-scale motion of the cloud core boundary is found using a tetrahedron decomposition technique, to reduce error due to the finite grid resolution. The cloud core here was defined as the volume containing vertical velocity exceeding $1 \mathrm{~m} \mathrm{~s}^{-1}$ and the sum of cloud water and cloud ice (excluding snow, graupel, and hail) mixing ratios exceeding $0.1 \mathrm{~g} \mathrm{~kg}^{-1}$. The definition of the cloud core has implications for the entrainment analysis and is discussed at the end of section $3 \mathrm{~b}$.

Following Moser and Lasher-Trapp (2017), the properties of the entrained or detrained air can be estimated by assigning a weight to the upstream air properties equal to the magnitude of the entrained flux:

$$
\frac{\left[\rho u W_{x(i+1, j, k)}-\rho u W_{x(i, j, k)}\right] a_{\mathrm{up}}+\left[\rho v W_{y(i, j+1, k)}-\rho v W_{y(i, j, k)}\right] a_{\mathrm{up}}+\left[\rho w W_{z(i, j, k+1)}-\rho w W_{z(i, j, k-1)}\right] a_{\mathrm{up}}}{\left[\rho u W_{x(i+1, j, k)}-\rho u W_{x(i, j, k)}\right]+\left[\rho v W_{y(i, j+1, k)}-\rho v W_{y(i, j, k)}\right]+\left[\rho w W_{z(i, j, k+1)}-\rho w W_{z(i, j, k-1)}\right]}
$$

where $a_{\text {up }}$ is the scalar value of the neighboring upstream grid cell (in the $x, y$, or $z$ directions) that was being entrained, $\rho$ is the moist air density, and $W$ is the surface area of the core on the faces of the grid cell.

\section{Results}

\section{a. General simulated cloud behavior}

In each simulation, the first thermals from the five heating functions reached the LCL and formed clouds after $35 \mathrm{~min}$ of forcing. The clouds (Fig. 4a) then repeatedly pulsed as new successive thermals rose from the subcloud layer, often into the wakes of preceding thermals, and the clouds progressively became taller with time, up to about $80 \mathrm{~min}$ (Fig. 5, left). The mean cloud-top heights of the closer-spaced clouds, that is, runs $4 \mathrm{KM}$ and $5 \mathrm{KM}$, experienced a noticeable lag in growth $(\approx 500 \mathrm{~m}$ difference in height) compared to the clouds spaced farther apart, especially before $70 \mathrm{~min}$, but this trend reverses after $80 \mathrm{~min}$ when all runs had begun precipitating. The slower cloud development in the $4 \mathrm{KM}$ and $5 \mathrm{KM}$ runs coincides with their weaker updrafts between 60 and $80 \mathrm{~min}$ (Fig. 5, right). Mimicking the trends in the cloud-top heights and maximum updraft speeds, the earliest surface rainfall from any individual cloud (Fig. 6) occurred from the runs with clouds spaced farther apart (8KM and 9KM) than those with the clouds forced closer together (4KM and 5KM). The maximum early (before $90 \mathrm{~min}$ ) rainfall varied between 6 and $8 \mathrm{~mm}$ across the runs.

Despite the initial slower development of precipitation in runs $4 \mathrm{KM}, 5 \mathrm{KM}$, and $5.5 \mathrm{KM}$, beyond $90 \mathrm{~min}$ some of their clouds produced another burst of rainfall that the simulations with larger cloud spacing were unable to duplicate. By the end of the simulation, runs $4 \mathrm{KM}$ and $5 \mathrm{KM}$ produced rainfall maxima near $25 \mathrm{~mm}$, but simulations with larger cloud spacing produced maxima only one-half as much. The mean cloud-top height was also higher in $4 \mathrm{KM}, 5 \mathrm{KM}$, and $5.5 \mathrm{KM}$ after $90 \mathrm{~min}$ (Fig. 5, left). These taller clouds and their associated greater rainfall resulted from a "second generation" of clouds that developed in the $4 \mathrm{KM}, 5 \mathrm{KM}, 5 \mathrm{KM}$ narrow, $5 \mathrm{KM}$ wide, and 5.5KM runs, when their convective lines appeared to start "filling in" (Fig. 4b). 
a. $70 \mathrm{~min}$

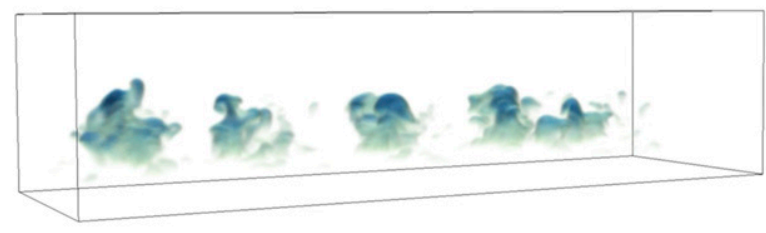

b. $110 \mathrm{~min}$

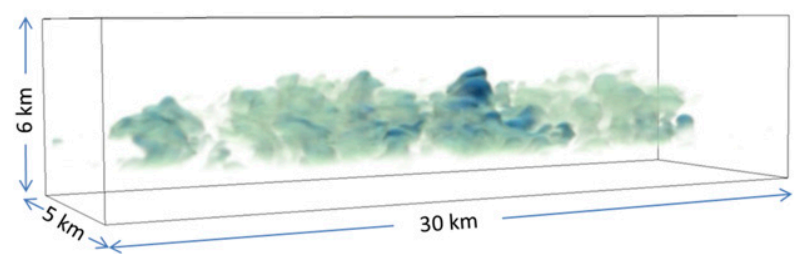

FIG. 4. Snapshots of cloud development for the 5KM simulation (showing cloud water only), with darker colors having greater cloud water content, at (a) 70 and (b) 110 min into the simulation. The dimensions are for scale and do not depict the full dimensions of the domain.

A second generation of clouds was absent in all the other simulations with greater distances between the clouds. To determine the underlying factor(s) behind these trends in the simulation results, the next sections explore the sensitivity of entrainment, dynamics, and microphysics to the distance between neighboring clouds.

\section{b. Entrainment before the first rainfall}

Entrainment and detrainment rates were calculated every $5 \mathrm{~s}$ for the $5 \mathrm{KM}-9 \mathrm{KM}$ runs and averaged over all the clouds over 2-min intervals beginning at 50,60, 70, and $80 \mathrm{~min}$ to analyze any differences before the first surface rainfall. Figure 7 displays entrainment (label E; top row) and detrainment (label $\mathrm{D}$; middle row) rates normalized over the surface area of the cloud, that is, the surface area bounding the 3D volume of the cloud between two successive vertical levels in the model, for the five runs over each of these 2-min periods. At $50 \mathrm{~min}$, when cloud-top heights were most similar across the runs, the calculated entrainment fluxes also varied little. Some variation does occur in entrainment among the different simulations as the time increased, especially for higher cloud tops, but overall there is no strong evidence of a systematic dependency of the entrainment rates on cloud separation. Detrainment rates are included for completeness in Fig. 7, but again do not show any striking dependence upon cloud separation distance apart from the differences in cloud-top heights. Thus, for these simulations with cloud radii $R=1 \mathrm{~km}$, with updraft centers separated by distances of greater than or equal to $5 R$, the mean turbulent entraining motions of these clouds are not affected by the presence of other nearby clouds. Distances of less than $5 R$ could not be tested because of limitations explained later in this section.

While the entrainment into the updrafts appears to be independent of the cloud spacing tested here, the cloudtop heights, maximum updraft speeds, and timing of rainfall suggest there may be a dependency of vertical mass flux upon the cloud spacing. Between 50 and 52 min when the cloud-top heights and maximum updraft speeds were most similar, the magnitude of the vertical mass fluxes (label M; Fig. 7, bottom row) are also very similar. Over the next $10-20 \mathrm{~min}$, however, when the mean cloud top and mean updraft speeds vary the most between simulations, a general increase in updraft mass flux with increasing cloud spacing is evident, despite the fact that the surface heating functions are of identical strength in all of the simulations. (By $80 \mathrm{~min}$, all simulations have precipitating clouds that
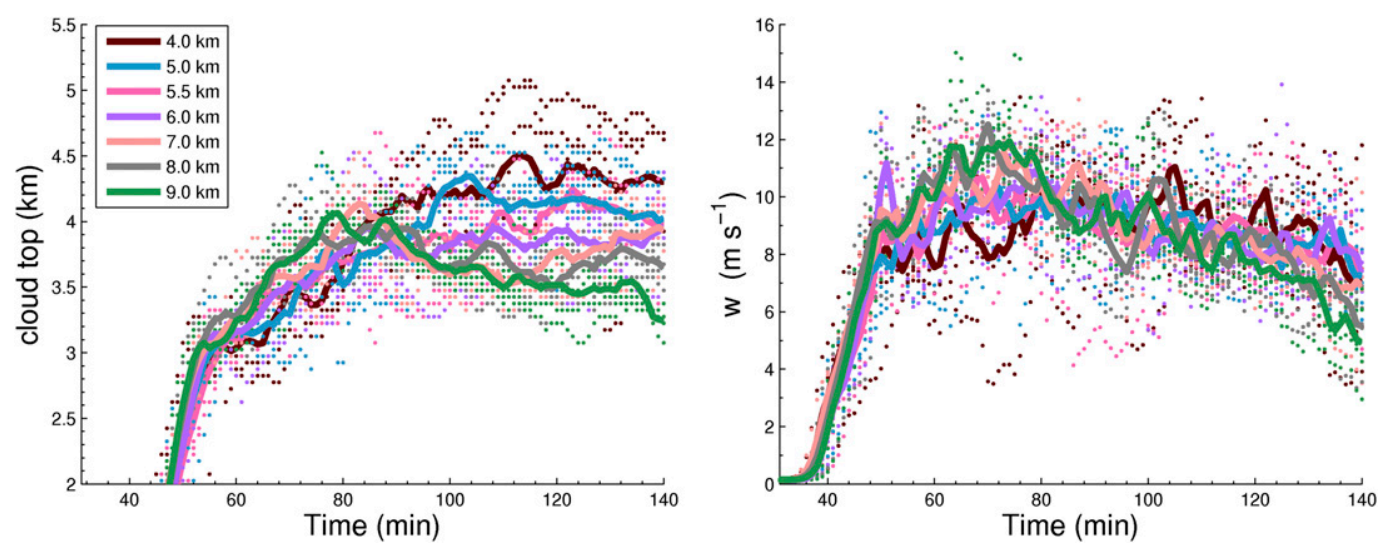

FIG. 5. Time series of the mean (lines) and maximum (dots) (left) cloud-top heights and (right) updraft speeds for each simulation. Each dot represents the maximum value over a single Gaussian-shaped heat flux, for a total of five maxima per case per time. 


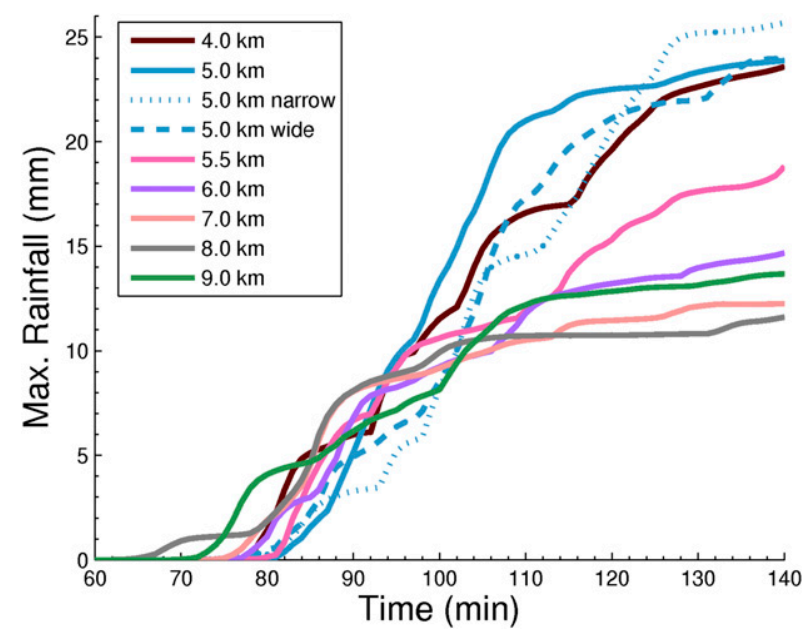

FIG. 6. Maximum rainfall at any surface grid point in the domain for each simulation, including two sensitivity tests with narrower and wider heat fluxes for the $5 \mathrm{KM}$ run as described in the text.

alter the vertical mass fluxes.) This dependency of updraft strength upon cloud proximity is due to the increased competition for subcloud inflow between closer clouds, weakening their updrafts, as found by Kogan and Shapiro (1996).

Although the entrainment profiles at these times were very similar, the characteristics of the air entrained and detrained may have been influenced by the cloud separation distance, affecting their LWC and thus precipitation formation, as well. The properties of the entrained, detrained, and cloudy updraft ("core") air were quantified using (2), following the method detailed in Moser and Lasher-Trapp (2017), and binned into cumulative distribution functions (CDFs). The calculated nonprecipitating total water content $q_{T}$ (i.e., water vapor, cloud water, and small ice mass combined) was normalized (denoted as $q_{T}^{*}$ ) using

$$
q_{T}^{*}=\frac{q_{T}-q_{T_{E}}}{q_{T_{\mathrm{CB}}}-q_{T_{E}}},
$$

where $q_{T_{\mathrm{CB}}}$ is the undiluted value of $q_{T}$ from below cloud base $\left(8.6 \mathrm{~g} \mathrm{~kg}^{-1}\right)$, and $q_{T_{E}}$ is the environmental $q_{T}$ at the sample altitude. A value of $q_{T}^{*}$ equal to 0 represents pristine environmental air at the sampling height, and a value of 1 represents undiluted air from below cloud base. Precipitating hydrometeors (e.g., aggregates, graupel, hail, and rain) were not included in these calculations because they are too large to follow with the entrained air. Other properties of the entrained, detrained and core air were also tracked: the fraction of the adiabatic liquid water content (ALWC) at the sample level, and perturbation values of the virtual potential temperature $\theta_{v}^{\prime}$, both computed using the environmental values at the sampling height.

Normalized CDFs of the $q_{T}^{*}$ in samples of entrained (red), detrained (blue), and core (black) air are presented in Fig. 8 for all runs over the various time periods. Entrained $q_{T}^{*}$ values encompassed a range of mixtures between undiluted and purely environmental air. The entrained samples have only subtle differences across the runs for each of the times. The values of the 25th, 50th, and 75th percentiles (solid red, dashed red, and solid red vertical lines, respectively) only deviated slightly at each time period (comparing within each column). The percentage of entrained parcels that contained precipitation content below $0.5 \mathrm{~g} \mathrm{~m}^{-3}$ (Fig. 8, parentheses) increased as the clouds began to develop precipitation but did not substantially affect the amount of LWC entrained (Fig. 9). No dependency upon cloud spacing is apparent in Fig. 9, where the percentiles of the entrained LWC/ALWC were nearly identical across the runs with different cloud spacing. Similar distributions of the $\theta_{v}^{\prime}$ of the entrained air (not shown) were also nearly identical among the runs. In summary, the calculations suggest the entrainment rates, and characteristics of the entrained air, in these simulations are unaffected by the proximity of neighboring clouds as they developed and produced the first convective rainfall.

The model setup and method of calculating entrainment used here limits the smaller range of cloud separation distances that can be tested. If the surface forcing for the clouds were moved even closer together (e.g., run $4 \mathrm{KM}$ ), the heating functions initiating the clouds would strongly overlap and lead to early cloud merging. In addition, because the defined cloud core surfaces must be separate entities, the individual cloud cores would no longer remain identifiable to the entrainment algorithm. Using a more restrictive definition of the cloud core, such as a minimum $1 \mathrm{~g} \mathrm{~kg}^{-1}$ condensed mass threshold, could help in this regard but makes it difficult in determining whether the entrained air was depleted of condensate by mixing or other microphysical processes (e.g., collection of the cloud water by larger precipitation particles). The choice of the lower condensate threshold of $0.1 \mathrm{~g} \mathrm{~kg}^{-1}$ used here focuses the analysis upon those parcels entrained at the periphery of the updraft where the entrainment of environmental air is more probable, and where the LWC of air parcels is less affected by microphysical sources and sinks.

\section{c. Microphysical properties of first-generation clouds}

The microphysical behavior in the first generation of clouds was similar across the runs. Time series of vertical profiles of maximum mass mixing ratios or number 

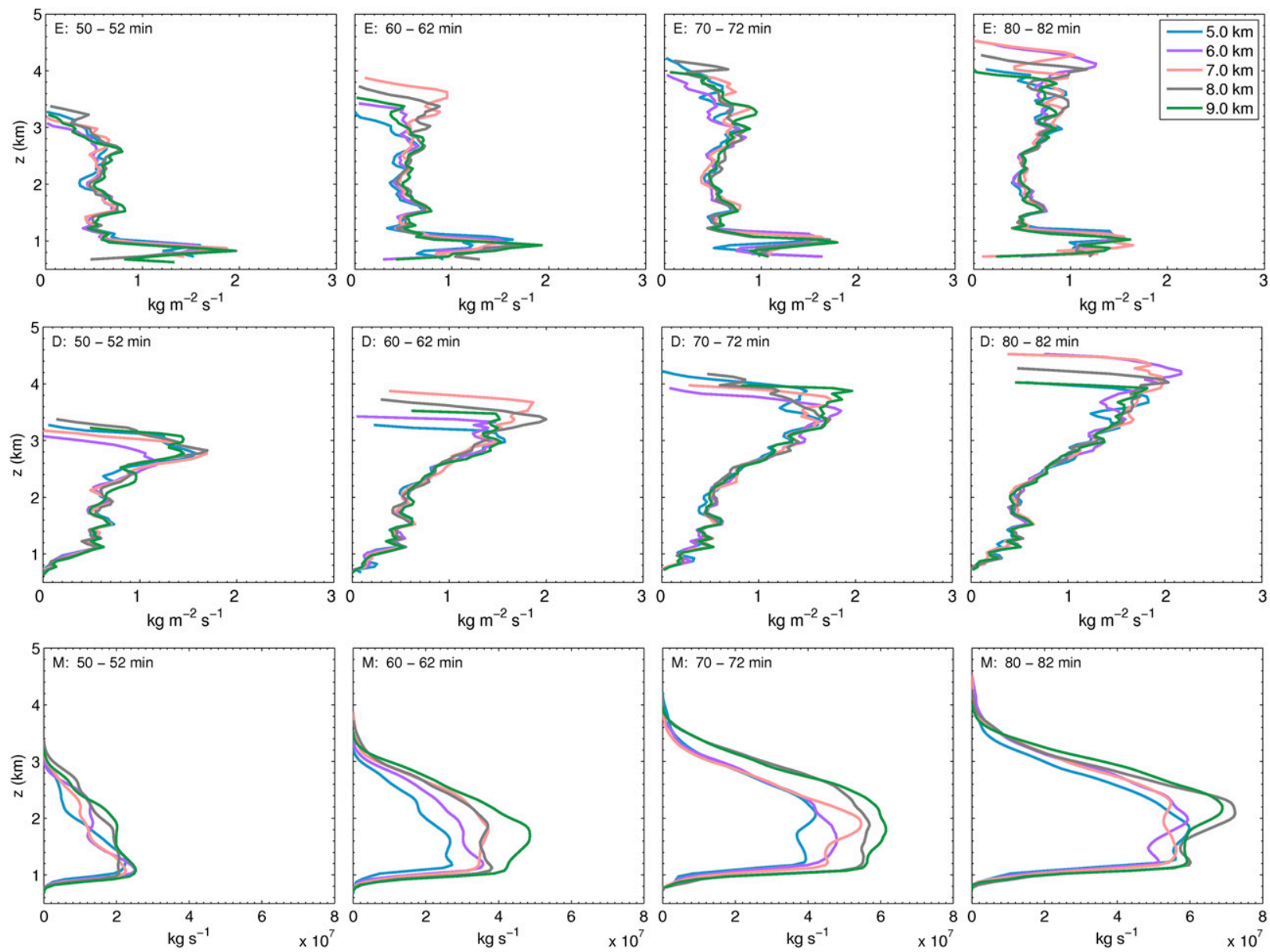

FIG. 7. Vertical profiles of the mean (top) entrainment (label E) and (middle) detrainment (label D) rates, normalized by the surface area of the cloud core at that height, and the (bottom) mean vertical mass flux (label M) for the 2-min periods labeled, for each of the simulations.

concentrations from a cloud within run 9KM are shown in Fig. 10 for illustration. The first raindrops were formed by collision-coalescence in thermals rising through a height of $3 \mathrm{~km}$ before the appearance of any ice (not shown). Initial rain amounts near cloud tops grew to $1-2 \mathrm{~g} \mathrm{~kg}^{-1}$ (Fig. 10d at $60 \mathrm{~min}$ ) as these thermals rose several hundred meters more before subsiding. Large increases in the rain production occurred when new thermals rose through existing cloud volumes containing newly formed raindrops. These preexisting collector drops benefited greatly from the arrival of nearly adiabatic turrets having high LWC not depleted yet by their own warm-rain process or entrainment (as seen by the proximity of the LWC curves to the adiabatic values in Fig. 10a). By 80 min, raindrop mixing ratios grew to larger than $4 \mathrm{~g} \mathrm{~kg}^{-1}$. Initial ice concentrations (Fig. 10b) were approximately $0.1 \mathrm{~L}^{-1}$ as the cloud tops ascended above $3.0 \mathrm{~km}\left(-4^{\circ} \mathrm{C}\right)$, as prescribed by the Meyers et al. (1992) parameterization for contact freezing. Limited graupel, totaling less than $0.01 \mathrm{~g} \mathrm{~kg}^{-1}$ (Fig. 10c), were formed from these ice particles by riming the supercooled cloud water. The Hallett-Mossop process was initiated as the graupel transited that temperature regime, and increased the maximum ice number concentrations to nearly $1 \mathrm{~L}^{-1}$ at a height of $3.2 \mathrm{~km}\left(-5^{\circ} \mathrm{C}\right)$. Consequently, the maximum graupel mixing ratios in these early clouds increased to a maximum of $0.1 \mathrm{~g} \mathrm{~kg}^{-1}$, although only a minor contribution to the surface rainfall upon melting. The rain, produced mainly by collisioncoalescence, typically occupied the updrafts, eventually producing strong negative buoyancy loading and facilitating their collapse.

\section{d. Subcloud convergence and second-generation clouds}

To understand the production of a second generation of clouds in some of the runs, the mean convergence below each cloud base was calculated over a 

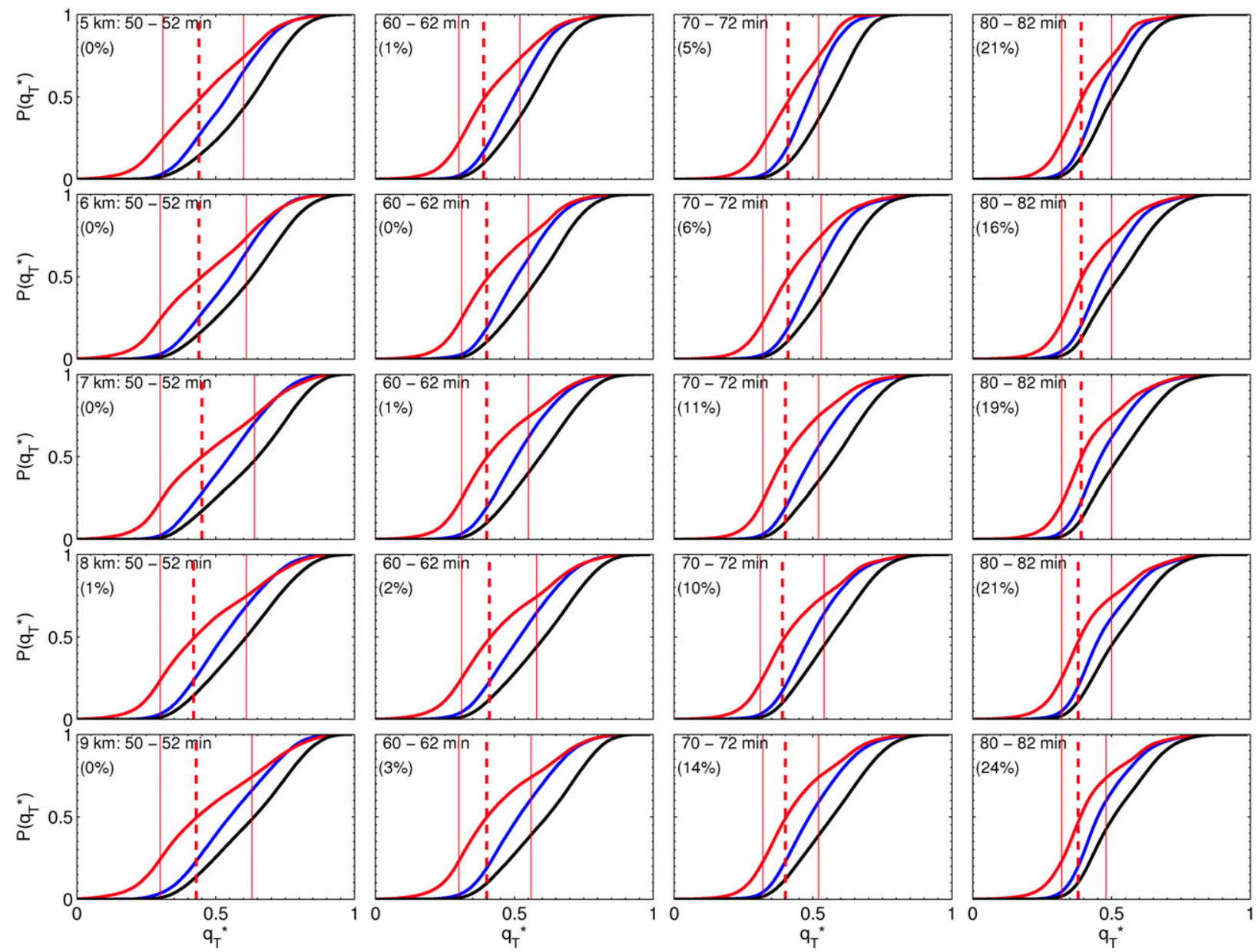

FIG. 8. CDFs of values of $q_{T}^{*}$ for samples of entrained (red curve), detrained (blue curve), or core (black curve) air for all of the clouds in a given simulation. Rows contain different times within the same simulation; columns correspond to the same time across all simulations. Vertical red lines represent the 25th, 50th, and 75th percentiles of values of $q_{T}^{*}$ for the sampled entrained air only. Values in parentheses are the percentage of entrained air samples containing precipitation content greater than $0.5 \mathrm{~g} \mathrm{~m}^{-3}$.

$4 \mathrm{~km} \times 4 \mathrm{~km} \times 0.8 \mathrm{~km}$ volume (the approximate volume of the boundary layer heating over each surface heat flux) and plotted as a time series for each cloud and each run in Fig. 11 (top row). For all the simulations, the magnitudes of the mean convergence before $70 \mathrm{~min}$ were very similar, except for the cloud farthest downwind of all the others (cloud 5). Before $90 \mathrm{~min}$, the initial amount of rainfall (Fig. 11, bottom row) shows little if any dependency on the spacing, varying between 4 and $9 \mathrm{~mm}$, but the timing of the rainfall tended to be earlier for increased cloud separation distance.

After the first rainfall (near $70 \mathrm{~min}$; Fig. 11, bottom row), the subcloud convergence (Fig. 11, top row) began to exhibit large differences between the closer spaced clouds (4KM, 5KM, 5.5KM, and 6KM runs) and those farther apart (7KM, 8KM, and 9KM runs). During runs $7 \mathrm{KM}-9 \mathrm{KM}$, the mean convergence for each cloud had generally reached its maximum magnitude by $80 \mathrm{~min}$ because of evaporative cooling of rain falling beneath the cloud bases, despite the fact that the surface heat fluxes were still operating. On the other hand, the mean subcloud convergence below clouds 2,3 , and 4 in runs $4 \mathrm{KM}-6 \mathrm{KM}$ continued to strengthen beyond $80 \mathrm{~min}$, reaching magnitudes sometimes double the earlier maxima in the $7 \mathrm{KM}-9 \mathrm{KM}$ runs. This increase in the subcloud convergence was due to the meeting of laterally propagating outflows between the original raindriven downdrafts of clouds 1 and 2, 2 and 3, and 3 and 4, and forced new updrafts in between the original clouds. Figure 12 illustrates the forcing of one such secondgeneration cloud in the 5KM run: At $85 \mathrm{~min}$ (Fig. 12a), cloud 3 and cloud 4 had begun to precipitate, and the precipitation-driven downdrafts eventually converged between the two clouds (Fig. 12b, yellow box), forming a new updraft and cloud ("cloud B"; Figs. 12c,d). These second-generation clouds were slightly deeper than the 

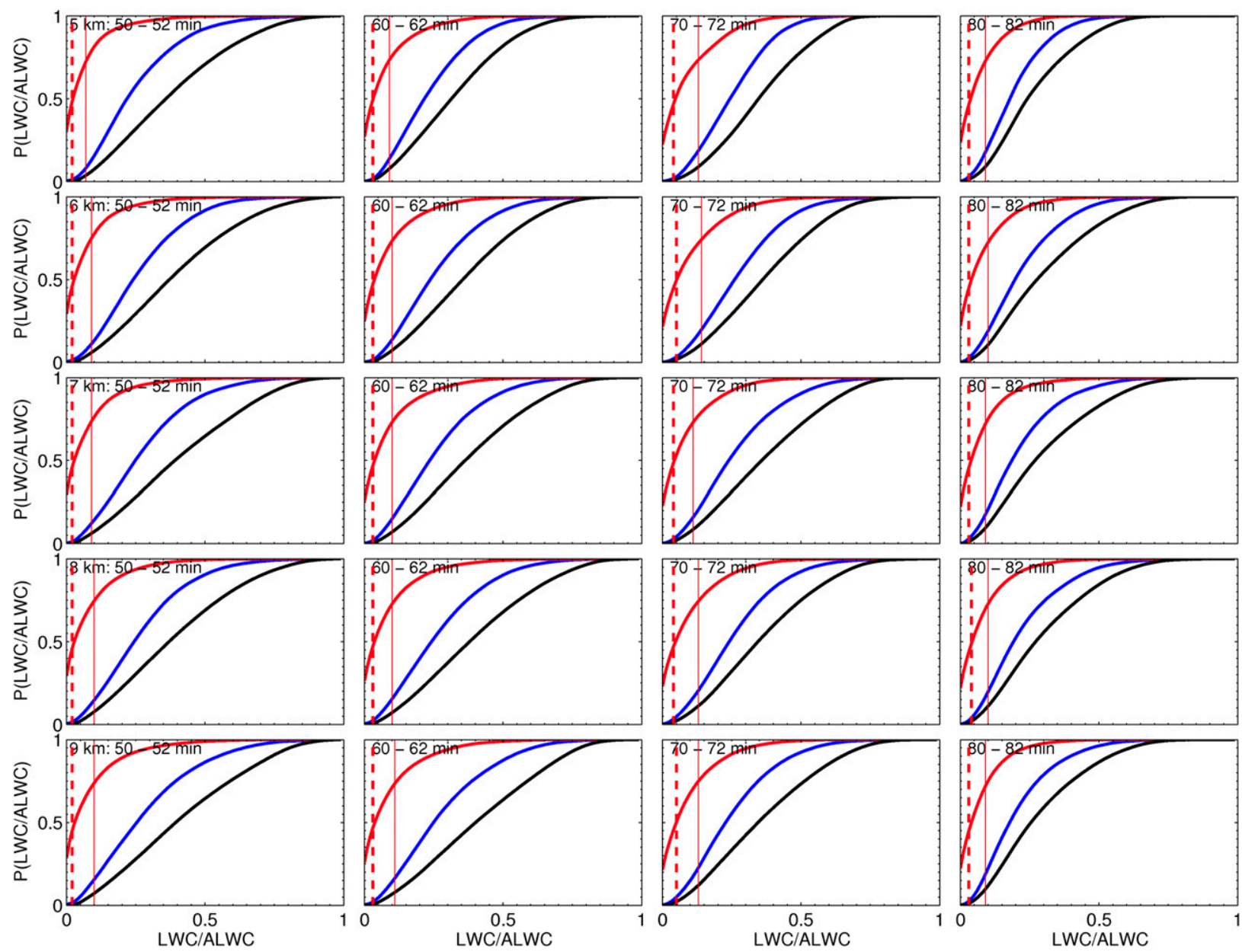

FIG. 9. As in Fig. 8, but for CDFs of the values of the fraction of LWC/ALWC.

first generation, but were still limited to $5 \mathrm{~km}$ height (Fig. 5) by a stable layer in the environment (Fig. 1). The second generation of clouds in the $4 \mathrm{KM}, 5 \mathrm{KM}$, and 5.5KM runs produced additional rainfall (Fig. 11, bottom row, partly reflected in the panels for clouds 2 , 3 , and 4 because they lie in between). The distances between the centers of the second-generation clouds and their parent clouds were approximately one-half of the distance between the centers of forcing $(\approx 2.5 \mathrm{~km}$ for run $5 \mathrm{KM}$, and $\approx 3 \mathrm{KM}$ for run $6 \mathrm{KM}$, i.e., $2.5 R$ and $3 R$, respectively, where $R$ is the cloud radius of $\sim 1 \mathrm{~km}$ ). The reduced spacing in these runs allowed the cloud boundaries between the first- and secondgeneration clouds to overlap or nearly overlap (as seen in Figs. 12c,d). These new clouds from the 5KM run, hereinafter referred to as "cloud A" (formed between clouds 2 and 3), and "cloud B" (formed between clouds 3 and 4; shown in Fig. 12) will be further examined because they produced the most rainfall.

\section{e. Entrained air into the second-generation clouds}

Because the edges of clouds A and B overlap or nearly overlap with the remnants of their "parent" clouds, and because their ascent occurred at a later time when the local environment may have been substantially humidified by detrainment from the first-generation clouds, the air they entrained could have differed from that diagnosed earlier in the simulations. To evaluate any evolution of the entrained air, time-height diagrams of the 25th percentile from the CDFs of $q_{T}^{*}$ at each altitude were compiled for runs $5 \mathrm{KM}, 6 \mathrm{KM}, 7 \mathrm{KM}, 8 \mathrm{KM}$, and 9KM (Fig. 13, first column), with lower $q_{T}^{*}$ values indicating more pristine environmental air being entrained. The 25th-percentile values are generally comparable across the runs before $100 \mathrm{~min}$, consistent with the results shown in Fig. 8. Beyond $100 \mathrm{~min}$, as the secondgeneration clouds develop in the $5 \mathrm{KM}$ and $6 \mathrm{KM}$ runs, the entrained air moistens, especially below $3 \mathrm{~km}$ (darker colors). This is also evident in the shift in 

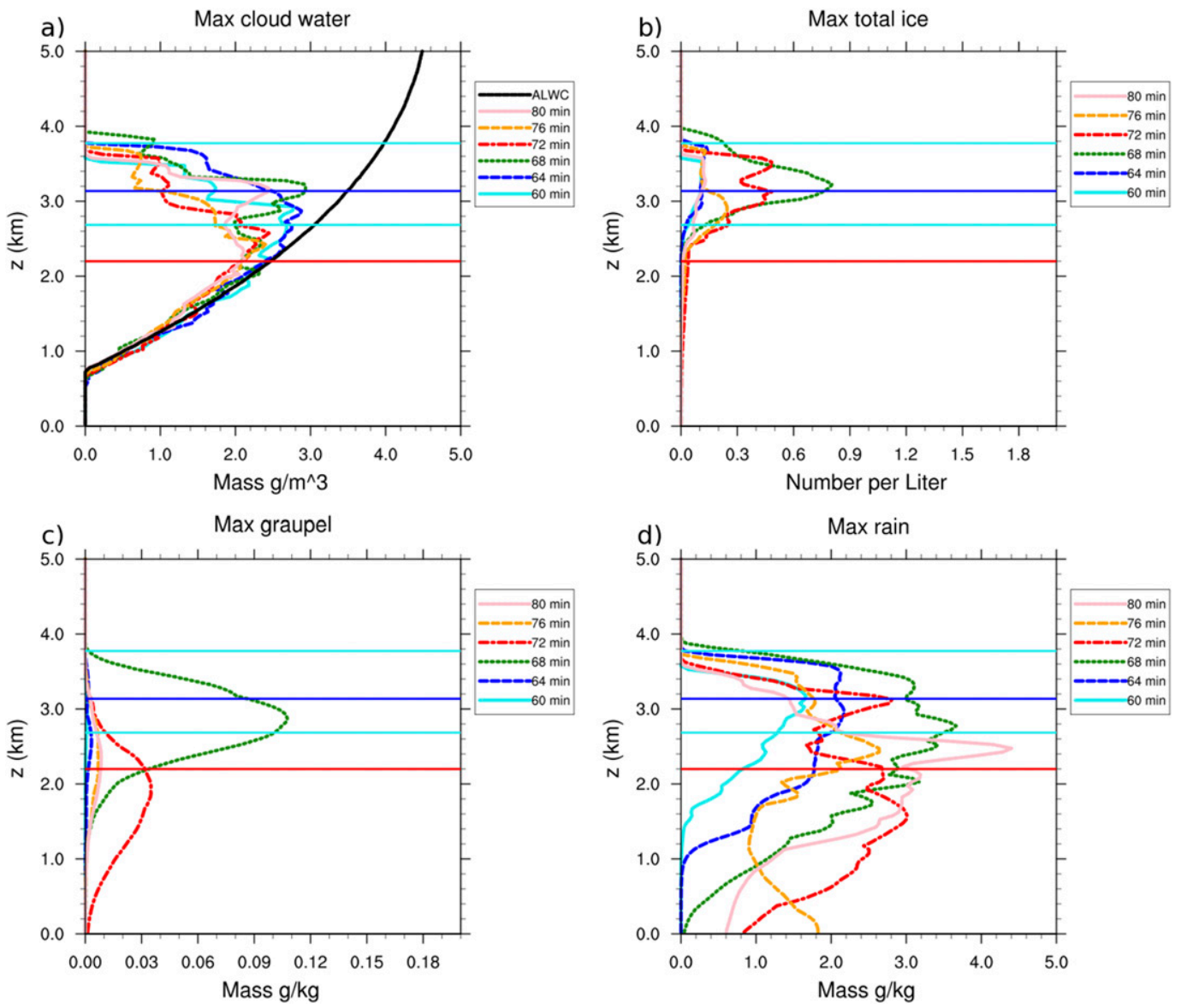

FIG. 10. Vertical profiles of the maximum (a) cloud LWC, (b) ice number concentration, (c) graupel mixing ratio, and (d) rain mixing ratio for cloud 1 in run 9KM. Adiabatic values of cloud water are shown by the thick black curve in (a). Horizontal lines in all panels denote environmental heights of the $0^{\circ} \mathrm{C}$ isotherm (red), Hallett-Mossop temperature zone from $-3^{\circ}$ to $-9^{\circ} \mathrm{C}$ (light blue), and $-5^{\circ} \mathrm{C}$ isotherm (dark blue).

quartiles for runs $5 \mathrm{KM}$ and $6 \mathrm{KM}$ toward higher $q_{T}^{*}$ (more humid) values (Fig. 13, second column). As was the case for the first-generation clouds, there are negligible differences in the amount of LWC in the entrained air (Fig. 13, third column).

However, there is some indication that the percentage of entrained air samples containing more than $0.5 \mathrm{~g} \mathrm{~m}^{-3}$ of precipitation increased in the runs for the closestspaced clouds (Fig. 13, labeled in parentheses): $21 \%$ and $33 \%$ of the entrained air samples in the $6 \mathrm{KM}$ and $5 \mathrm{KM}$ runs, respectively, met this criterion. These percentages are equivalent to or exceed the first-generation clouds (Fig. 8): some precipitation would have originated in the second-generation clouds, as indicated by the values with larger cloud spacing, but some may also be remnants from the first generation. The high frequency of precipitation in the entrained parcels in the $5 \mathrm{KM}$ and $6 \mathrm{KM}$ runs suggests a potential microphysical impact of entraining precipitating hydrometeors into the second-generation clouds could be important and is addressed in section 3f. Quantifying the entrainment of precipitating hydrometeors would require a different framework than used here to evaluate the entrained air, as large hydrometeors would not necessarily follow the flow of the entraining eddies.

Changing the widths of the heat fluxes used in the $5 \mathrm{KM}$ run produced the expected trends in the characteristics of the entrained air (not shown). Widening the heat flux slightly humidified the entrained air and increased the percentage of entrained samples containing precipitation $(41 \%)$ because of the greater cloud-edge overlap with the first-generation clouds. Narrowing the heat flux slightly dried the entrained air and substantially lowered the percentage of entrained samples with precipitation (19\%) because of less cloud-edge overlap. Thus, while no entrainment dependency upon cloud spacing was evident for the first-generation clouds, the entrained air into the second-generation clouds 

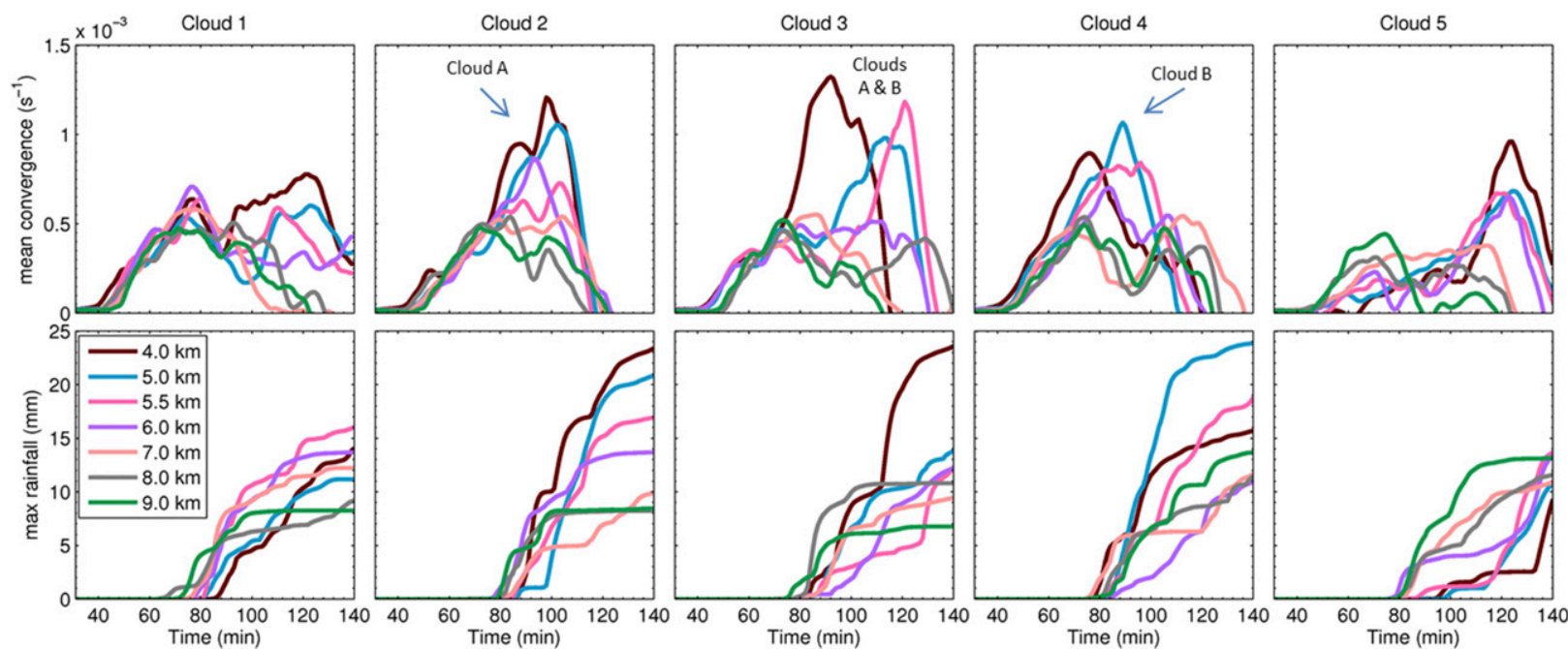

FIG. 11. Time series of the (top) mean subcloud convergence for each of the five clouds in each run and (bottom) maximum surface rainfall, all calculated over a $4 \mathrm{~km} \times 4 \mathrm{~km} \times 0.8 \mathrm{~km}$ volume centered over the cloud forcing. Labels and arrows denote contributions from second-generation clouds ( $\mathrm{A}$ and $\mathrm{B}$ ) in some simulations that formed between the original forcing functions.

demonstrates a minor influence by their closer mutual proximity. The differences between CDFs of the entrained $q_{T}^{*}$, LWC, and $\theta_{v}^{\prime}$ are not large, but Kolmogorov-Smirnov tests using $O\left(10^{6}\right)$ samples of the entrained air ensured they were nonidentical to a $p$ value of 0.01 .

\section{f. Microphysical properties of second-generation clouds}

The microphysical pathway to precipitation of the second-generation clouds sometimes differed from the first generation. Two examples are illustrated as a series of vertical profiles in Fig. 14 using cloud A and cloud B in the default run $5 \mathrm{KM}$.

In both clouds $\mathrm{A}$ and $\mathrm{B}$, supercooled cloud water was initially abundant between $3\left(-4^{\circ} \mathrm{C}\right)$ and $4 \mathrm{~km}\left(-10^{\circ} \mathrm{C}\right)$, much like the first generation. After the cloud tops reached $4.6 \mathrm{~km}$ (Figs. 14a,b), however, only the supercooled LWC in cloud B persisted. In cloud A, the LWC decreased substantially within the Hallett-Mossop zone and above because of more active ice processes, as discussed below.

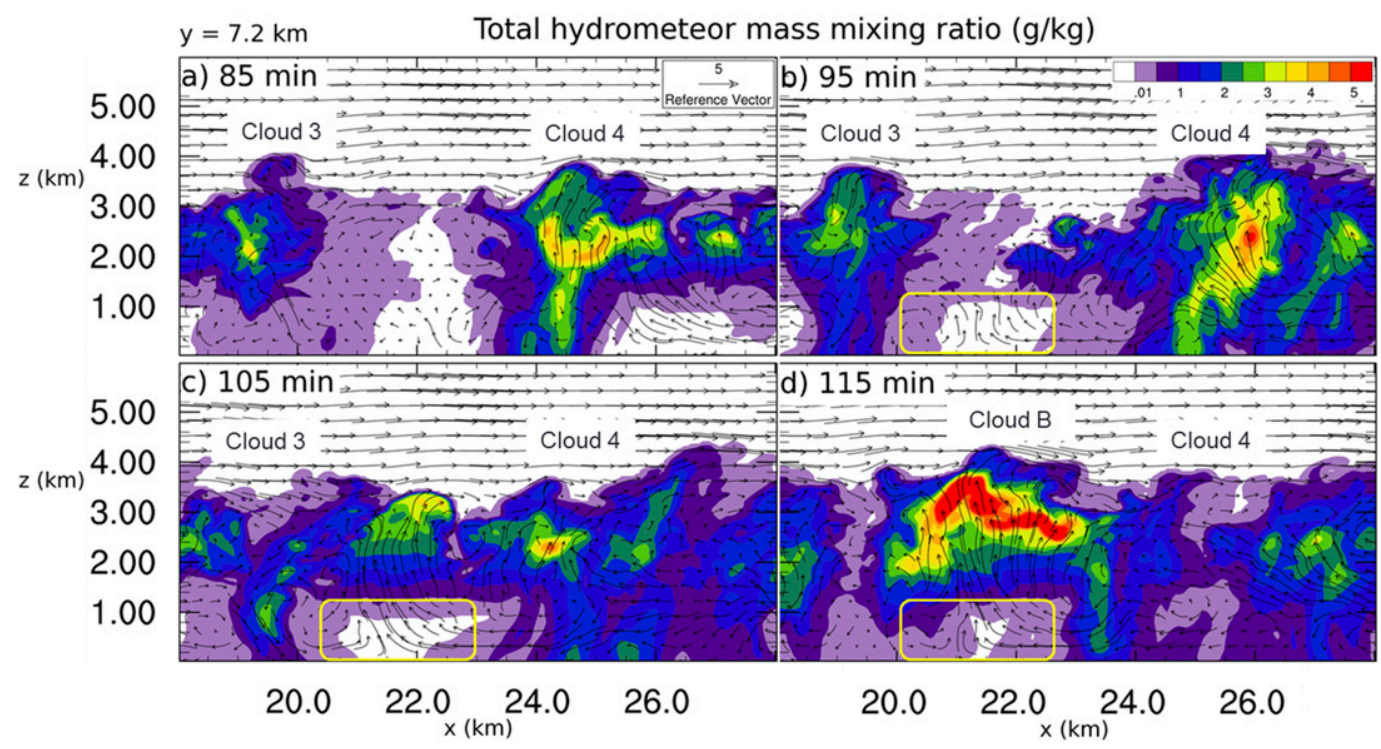

FIG. 12. Vertical cross sections of the total hydrometeor mass mixing ratio [filled contours; scale at upper right of (b)] with in-plane velocity vectors overlaid, for clouds 3 and 4 of the 5KM run at 10-min intervals. The secondgeneration subcloud updraft for cloud B is outlined with a yellow box. 

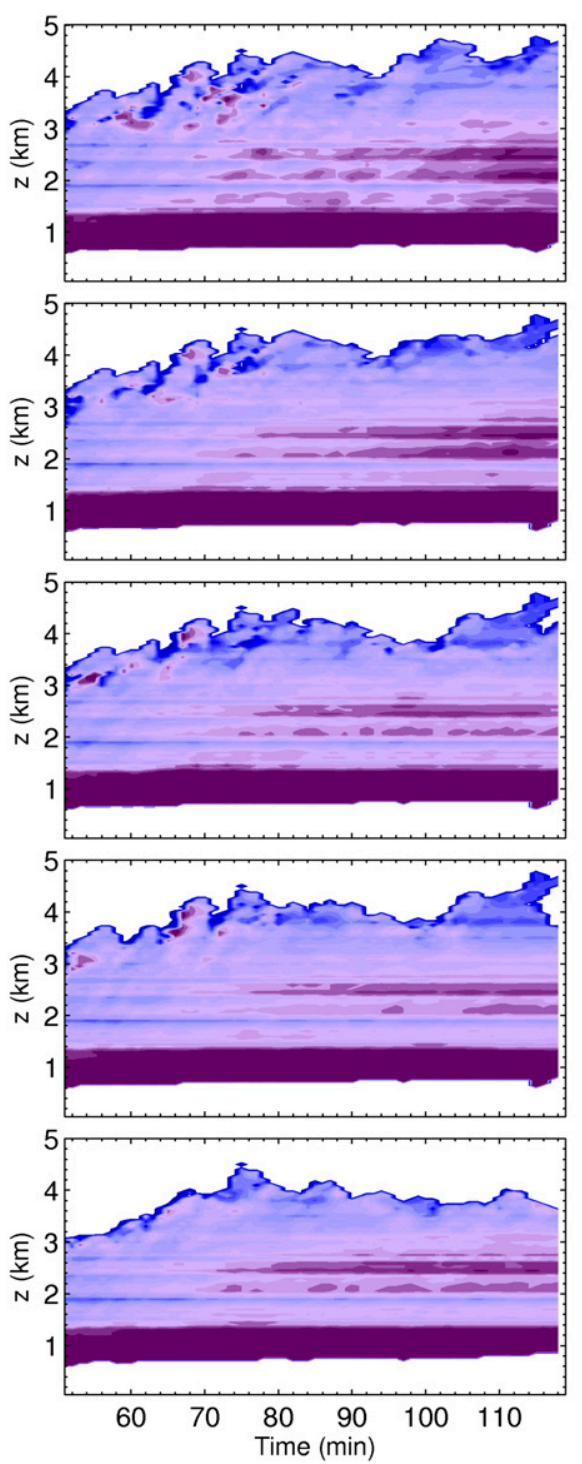
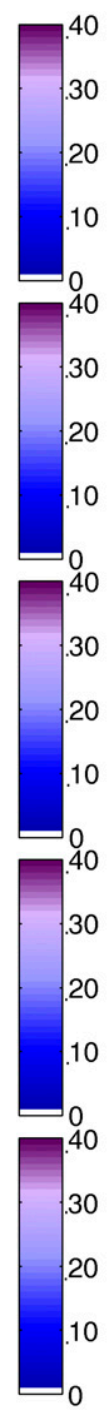

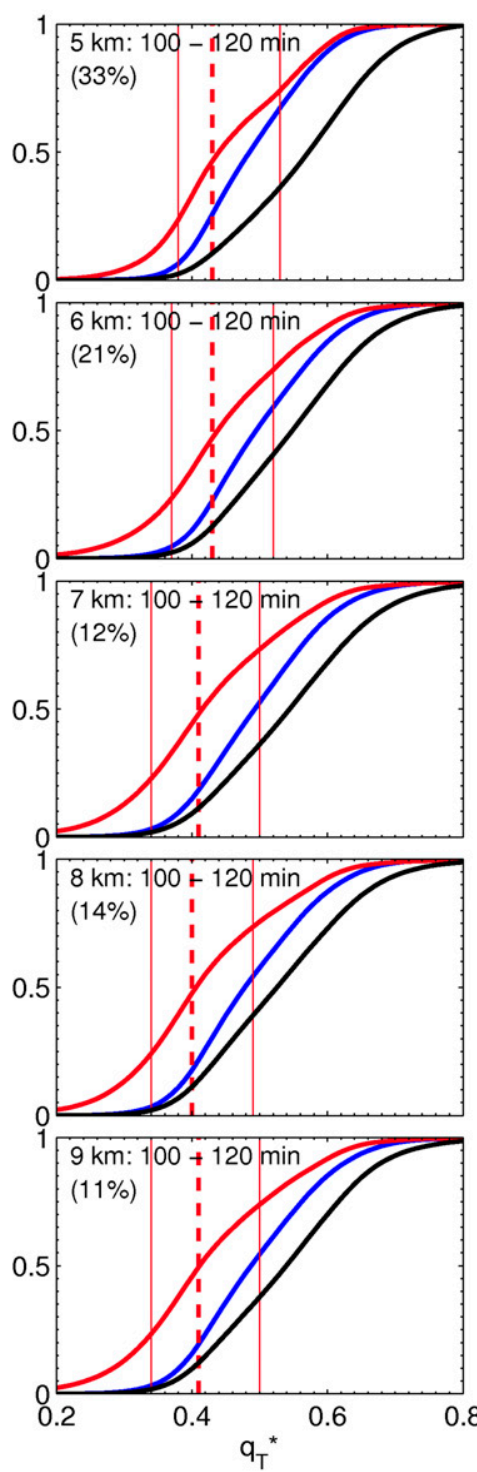

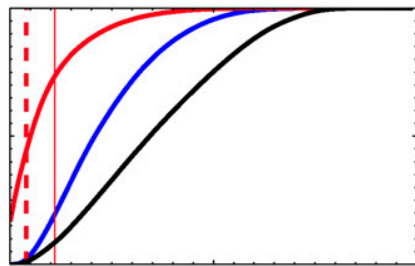
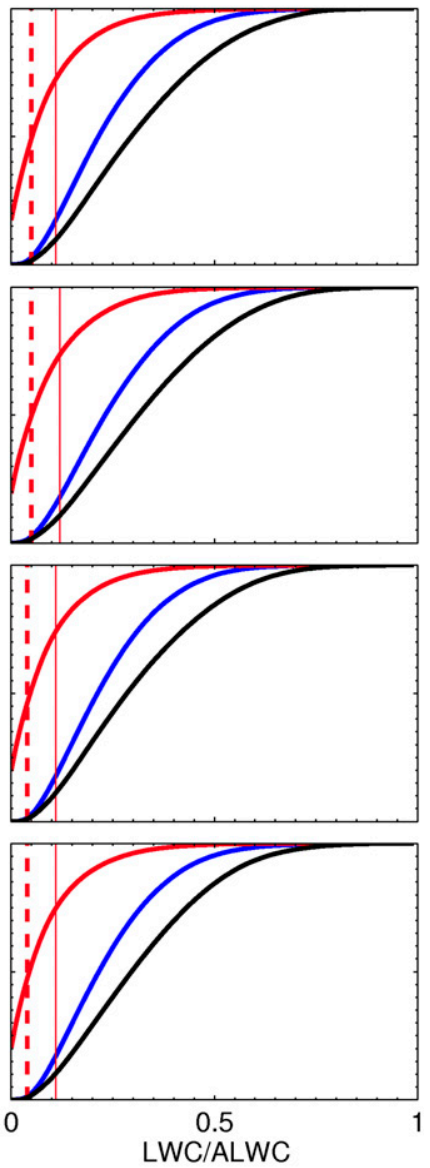

FIG. 13. (left) Time-height diagrams of the 25th-percentile entrained value of $q_{T}^{*}$. (center), (right) As in Figs. 8 and 9, but between 100 and $120 \mathrm{~min}$ for sampled air between cloud base and 3-km height.

Unlike the first-generation clouds, clouds A and B did not ascend into clear environmental air. Small concentrations of ice crystals were advected from upstream clouds into the rising (and entraining) tops of clouds A and B. While this residual ice was not exceedingly plentiful, it helped increase the total amount of small ice crystals to $1 \mathrm{~L}^{-1}$ in cloud A and $0.5 \mathrm{~L}^{-1}$ in cloud B (Figs. $14 \mathrm{c}, \mathrm{d}$ at $105 \mathrm{~min}$ ), approximately an order of magnitude higher than that attributable to primary ice nucleation alone. The initial amount of ice in cloud A, partly attributable to ingesting residual ice from the first-generation clouds, surpassed the maxima produced in any of the first-generation clouds (Fig. 10b). Thus, while the strength of entrainment and the characteristics of the entrained air did not differ substantially from the first-generation clouds, the entrainment of additional ice crystals from the earlier upwind clouds had some importance, as discussed next.

Only very small amounts of graupel $\left(0.1 \mathrm{~g} \mathrm{~kg}^{-1}\right.$ and $0.1 \mathrm{~L}^{-1}$ ) were initially present in clouds $\mathrm{A}$ and $\mathrm{B}$ (Figs. 14e,f), but in time the graupel in cloud A increased dramatically. Some were falling out and contributed to the surface rainfall, while others remained within the updraft. Like the first generation of clouds, the HallettMossop process first became active when graupel and supercooled water coexisted between $-3^{\circ}$ and $-8^{\circ} \mathrm{C}$, as cloud tops transited this temperature regime. From 105 to $114 \mathrm{~min}$ within the Hallett-Mossop zone, ice concentrations in cloud $\mathrm{A}$ increased to $16 \mathrm{~L}^{-1}$, graupel 

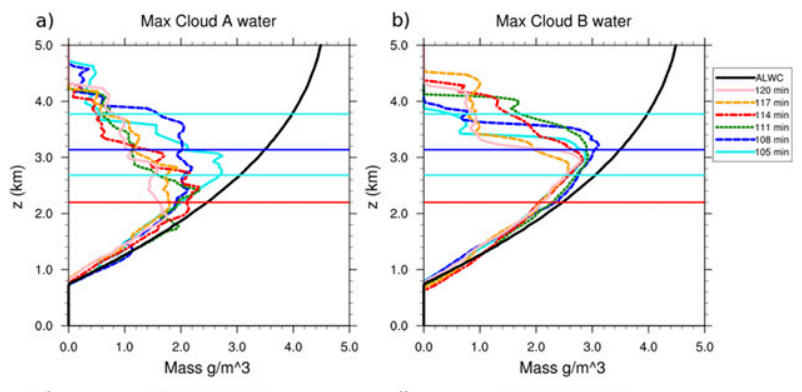

number and mass increased to $1 \mathrm{~L}^{-1}$ and $1 \mathrm{~g} \mathrm{~kg}^{-1}$, and supercooled cloud water decreased to less than $2 \mathrm{~g} \mathrm{~m}^{-3}$ as a result of the riming graupel. In contrast, cloud B showed very little ice multiplication, with cloud ice maxima of only $2 \mathrm{~L}^{-1}$ once the cloud top was collapsing, and graupel number and mass only reached maxima of $0.15 \mathrm{~L}^{-1}$ and $0.6 \mathrm{~g} \mathrm{~kg}^{-1}$. The difference was simply that the graupel in cloud A fell through regions of the cloud where the LWC was higher (verified in cross sections; not shown), while for cloud B the graupel fell mainly outside of the high LWC region. As a result, graupel concentrations and mixing ratios substantially increased in cloud $\mathrm{A}$ from the first-generation clouds, a near tenfold increase in graupel mass, despite a cloud-top height increase of only $200 \mathrm{~m}$.

Because of the difference in the activity of ice processes in clouds $\mathrm{A}$ and $\mathrm{B}$, the rain production also differed. Early in the lifetime of clouds A and B, raindrops formed similar to the first generation, as young turrets ascended through the 3.0-km level (not shown). Rain water mixing ratios in cloud $\mathrm{A}$ at $108 \mathrm{~min}$, the time when the Hallett-Mossop process began, peaked at $4 \mathrm{~g} \mathrm{~kg}^{-1}$ right above the $0^{\circ} \mathrm{C}$ level (Fig. 14i) and contributed to graupel production by colliding with the small ice and freezing to form graupel, or being collected by graupel already present, increasing its mass. Rain in cloud A began to fall earlier than cloud $\mathrm{B}$, and by $114 \mathrm{~min}$ the rain rate intensified as the majority of the melting graupel and rainwater precipitated from the base of the cloud (near $0.7 \mathrm{~km}$ ), with rainfall values approximately double of the first generation. On the other hand, cloud B exhibited vigorous warm-rain development through much of the cloud depth (Fig. 14j), as ice processes were much less active. The low amounts of ice and relatively high amounts of liquid water created an environment conducive to the rapid growth of supercooled raindrops by collision-coalescence. The updraft of cloud B was stronger and was sustained longer than that of cloud A, increasing the time raindrops could be suspended and grow by collision-coalescence (Fig. 15). By $115 \mathrm{~min}$ into the simulation, the rain formed in cloud A was already falling through the updraft, while the updraft of cloud B continued to suspend large amounts of rain in the upper portions of the cloud. Consequently, the maximum rain mixing ratio in cloud $\mathrm{B}$ grew from 4 to over $12 \mathrm{~g} \mathrm{~kg}^{-1}$ in $5 \mathrm{~min}$, producing much more rain mass and 2 times as much rainfall as any first-generation clouds (Figs. 10d and 6). Interestingly, it also produced $25 \%$ more rainfall than the graupel-dominated microphysical pathway to rainfall in cloud A.

FIG. 14. As in Fig. 10, but comparing time evolution of vert profiles for (left) cloud A and (right) cloud B of the maximum (a),(b) LWC, (c),(d) ice number concentration, (e),(f) graupel number concentration, and $(\mathrm{g}),(\mathrm{h})$ graupel and $(\mathrm{i}),(\mathrm{j})$ rain mixing ratios in run $5 \mathrm{KM}$.

\section{Summary and discussion}

The dynamical and microphysical characteristics of 3D simulated cumulus congestus clouds, with updraft 

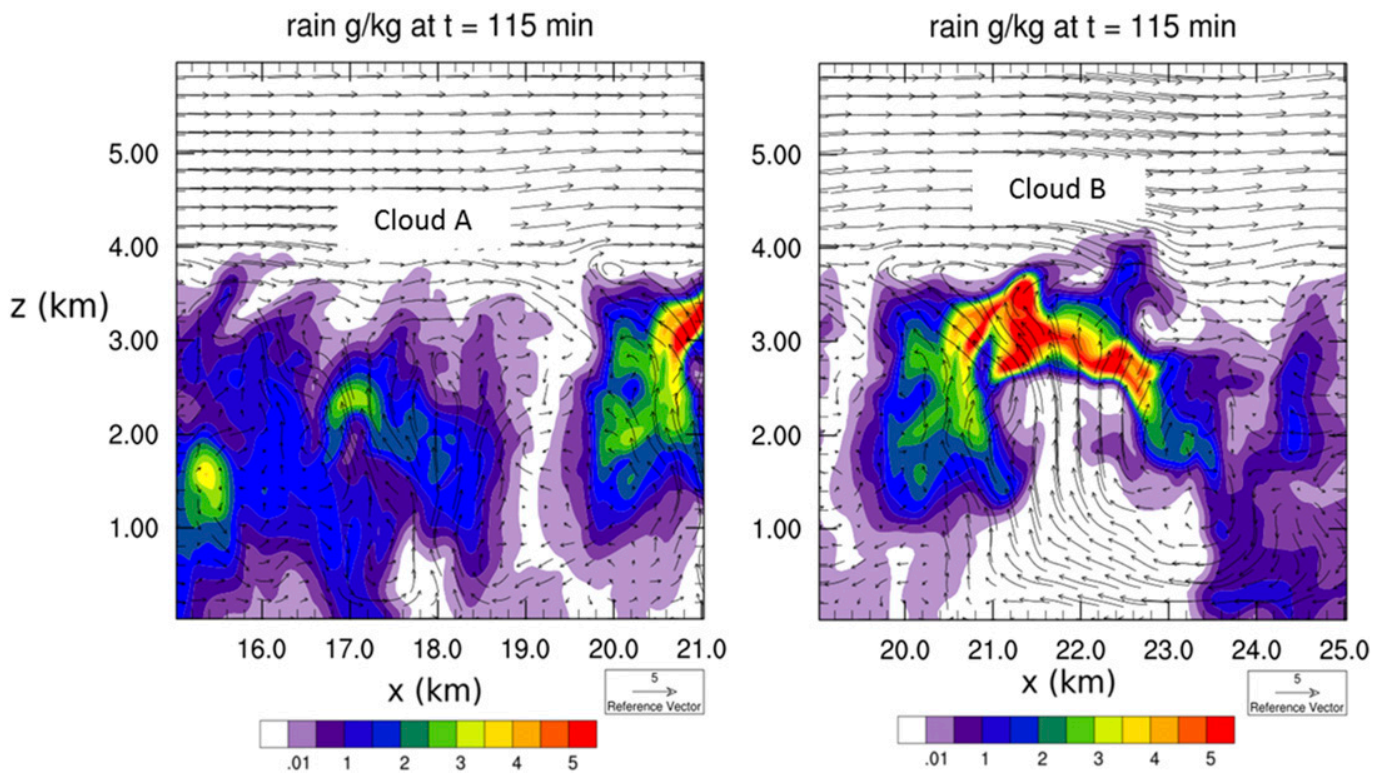

FIG. 15. Vertical cross sections of the rain mixing ratio $\left(\mathrm{g} \mathrm{kg}^{-1}\right)$ for (left) cloud A and (right) cloud B in run 5KM with in-plane wind vectors $\left(\mathrm{m} \mathrm{s}^{-1}\right)$ overlaid.

centers separated by distances ranging from 4 to 9 times the updraft radius, were compared to better understand how clouds developing in close proximity might differ from those that develop in relative isolation. The simulated clouds were part of an organized convective line that produced some surface rainfall in all cases but at different rates depending upon the cloud separation distance. This study is one of the first to quantify how much the cloud spacing can alter entrainment rates or the characteristics of the entrained air.

The main findings of this study are as follow:

- The magnitude of the directly calculated entrainment into clouds initiated along a line showed no dependence upon their separation distance, at least down to distances between the centers of clouds of 5 times their updraft radius $R$. The properties of the air they entrained also showed no systematic differences in total moisture, cloud water, or buoyancy.

- The timing of the first rainfall showed an inverse dependence upon cloud separation distance, being later for clouds with centers spaced less than $6 R$ because of increased competition for subcloud inflow that weakened cloud updrafts, an effect found in a previous study (Kogan and Shapiro 1996). Separation distances of less than $5 R$ led to early cloud merging.

- When the distance between the centers of neighboring, precipitating clouds was less than $6 R$, their outflows propagated outward and converged, forcing more vigorous clouds between the original clouds, creating a "cloud bridge" (Simpson et al. 1980).
- The second-generation clouds showed a minor tendency to entrain air that was more humid as a result of their closer proximity to their parent clouds; it seems unlikely to have been important to precipitation development.

- The second-generation clouds had slightly higher cloud tops, but their ingestion of residual ice blowing downwind from the first-generation clouds and possibly residual precipitation, as suggested in some past studies (e.g., Roesner et al. 1990; Blyth and Latham 1997), was capable of producing a stronger HallettMossop process and thus more ice, more graupel, and ultimately more rainfall than the first-generation clouds. Some second-generation clouds did not follow this pattern but simply had a stronger warm-rain process than the first-generation clouds because of their stronger updrafts and greater longevity.

Determining the applicability of these results to the specific 3 August case observed during COPE, upon which this study was based, is made difficult by the idealized nature of the modeling, but they do replicate some of the trends in the observations. The simulated clouds were forced in a prescribed, artificial manner instead of evolving naturally from a general line of convergence as observed during COPE, limiting the variability of the timing and convective development of individual cumulus clouds relative to their neighbors that occurred in reality. The simulated clouds were less deep than the tallest clouds $(\sim 6 \mathrm{~km})$ observed by the ground-based X-band radar, but do reproduce many of 
the shallower clouds observed on this day (Leon et al. 2016; Plummer et al. 2018). Taylor et al. (2016) and Jackson et al. (2018, manuscript submitted to Atmos. Chem. Phys. Discuss.) noted that precipitation was mainly formed by the warm-rain process for cloud tops warmer than $-10^{\circ} \mathrm{C}$, a result supported by the strong warm-rain process below the $-10^{\circ} \mathrm{C}$ isotherm in the simulations presented here. An active Hallett-Mossop process was also present in these simulations as implied by the observations on 3 August (Taylor et al. 2016; Jackson et al. 2018, manuscript submitted to Atmos. Chem. Phys. Discuss.), although it was weaker than some of the more dramatic cases observed in clouds with higher (colder) tops. The shallower cloud tops simulated here also prevented rain drops from being lofted to lower temperatures where they would be more likely to freeze, limiting simulated graupel number concentrations. Thus, the results of these simulations are representative of a subset of the weaker convection on 3 August 2013.

The lack of a trend in humidification of the entrained air as clouds were moved closer together was a surprising result that warrants more study. When clouds were forced closer together in the simulations conducted here, their updrafts merged early and were otherwise indistinct to the entrainment algorithm and thus could not be identified as separate entities. These results, when compared with the much stronger humidification of the entrained air found in simulations of successive thermals within a single cumulus cloud (Moser and Lasher-Trapp 2017), suggest the rise of successive thermals through a cloud is a much more important factor in determining the rate of dilution of its core by entrainment.

For closer cloud spacing, as in the $4 \mathrm{KM}$ run, early mergers of updrafts occurred, which may be interpreted as neighboring clouds entraining each other. Any potential slowing of updraft dilution, by lowering the perimeter-to-area ratio via updraft merging as shown by Glenn and Krueger (2017), was offset by the competing radial inflows into neighboring updrafts like those simulated by Kogan and Shapiro (1996), and by the negative forcing of precipitation loading. The major rainfall event in run $4 \mathrm{KM}$ ultimately originated from a secondgeneration cloud forced by the converging of outflows from the first-generation clouds, similar to the cloudbridge mechanism described by Simpson et al. (1980). Although some updraft merging had occurred in the first-generation clouds in that simulation, it did not significantly enhance the precipitation from those clouds. More study of cloud mergers in their early stages and the competing effects is warranted.

While the entrained air into the second-generation clouds was slightly moistened by the decreased cloud proximity, the extent of this effect appears to be marginal here, and the significance of its overall impact on rainfall seems minimal. Of greater importance to rainfall is determining microphysical factors that can strengthen precipitation outflows to create new convection. In addition, it is also important to recognize factors that affect the presence of residual small ice or residual precipitation from older neighboring clouds that is collocated with the entrained air. Both issues are beyond the scope of this study. Although some experimentation was begun to investigate how microphysical changes might alter the precipitating cloud outflows, the cloud dynamics were similarly modified, and thus a different approach is needed. Similarly, the algorithms used here to diagnose entrainment are incapable of quantifying the amount of the residual ice and precipitation ingested by the nextgeneration clouds; a model that tracks the trajectories of precipitation-sized particles (e.g., Naumann and Seifert 2016; Hoffmann et al. 2017) might be of use in this regard.

The large sensitivity of the convective rainfall to cloud spacing in this study places additional importance on the organization of convection, in particular to the spacing of clouds and their outflows. While the close clustering of clouds showed a slight tendency to entrain more humid mixtures in these simulations, weakly supporting the "near environment" hypothesis (Böing et al. 2012; Feng et al. 2015), the dynamical interaction of intersecting precipitation outflows is deemed here to be more important for convective rainfall than the entrainment effects. Mapes and Neale (2011) proposed a time dependency of the subgrid-scale organization of convection, where the early convection is shallow and suppressed by entrainment, but the preconditioning of the local environment and precipitation outflow interactions increase organization over time, leading to deeper convection and better reproducing the observed variability of convective rainfall (e.g., Fritsch and Carbone 2004). The dependency of convective rainfall, and to a lesser extent entrainment, on the organization of convection in the modeling simulations here supports the need for a timedependent, organization-related parameter in convective parameterizations as advocated by Mapes and Neale (2011). However, similar analyses over many more thermodynamic environments, wind shear profiles, and successive generations of convection are required to test the generality of this work toward developing better convective parameterizations.

Acknowledgments. Dr. George Bryan generously supplied his cloud model that made this work possible. Calculations were performed on the Blue Waters sustained-petascale computer, maintained by the National Center for Supercomputing Applications, also 
supported by the National Science Foundation (Awards OCI-0725070 and ACI-1238993) as well as the State of Illinois. Some computations were also performed on the University of Illinois School of Earth, Society and Environment Keeling computer cluster. The participants of the COPE field campaign collected observations of the 3 August 2013 case upon which these simulations are loosely based. Support for this study, and the authors' participation in the COPE field campaign, was from NSF Award AGS-1230292. Useful input was provided by Drs. Jeff French, Robert Trapp, and Robert Rauber. Three anonymous reviewers also helped to improve the clarity of the paper in its final form.

\section{REFERENCES}

Barthold, F. E., T. E. Workoff, B. A. Cosgrove, J. J. Gourley, D. R. Novak, and K. M. Mahoney, 2015: Improving flash flood forecasts: The HMT-WPC Flash Flood and Intense Rainfall Experiment. Bull. Amer. Meteor. Soc., 96, 1859-1866, https:// doi.org/10.1175/BAMS-D-14-00201.1.

Bigg, E. K., 1953: The supercooling of water. Proc. Phys. Soc., 66B, 688-694, https://doi.org/10.1088/0370-1301/66/8/309.

Blyth, A. M., 1993: Entrainment in cumulus clouds. J. Appl. Meteor., 32, 626-641, https://doi.org/10.1175/1520-0450(1993)032<0626: EICC $>2.0 . \mathrm{CO} ; 2$

—_, and J. Latham, 1993: Development of ice and precipitation in New Mexican summertime cumulus clouds. Quart. J. Roy. Meteor. Soc., 119, 91-120, https://doi.org/10.1002/ qj.49711950905.

—_ and - 1997: A multi-thermal model of cumulus glaciation via the Hallett-Mossop process. Quart. J. Roy. Meteor. Soc., 123, 1185-1198, https://doi.org/10.1002/qj.49712354104.

- S. G. Lasher-Trapp, and W. A. Cooper, 2005: A study of thermals in cumulus clouds. Quart. J. Roy. Meteor. Soc., 131 1171-1190, https://doi.org/10.1256/qj.03.180.

Böing, S. J., H. J. J. Jonker, A. P. Siebesma, and W. W. Grabowski, 2012: Influence of the subcloud layer on the development of a deep convective ensemble. J. Atmos. Sci., 69, 2682-2698, https://doi.org/10.1175/JAS-D-11-0317.1.

Bryan, G. H., and J. M. Fritsch, 2002: A benchmark simulation for moist nonhydrostatic numerical models. Mon. Wea. Rev., 130 2917-2928, https://doi.org/10.1175/1520-0493(2002)130<2917: ABSFMN $>2.0 . \mathrm{CO} ; 2$.

Carpenter, R. L., K. K. Droegemeier, and A. M. Blyth, 1998: Entrainment and detrainment in numerically simulated cumulus congestus clouds. Part I: General results. J. Atmos. Sci., 55, 3417-3432, https://doi.org/10.1175/1520-0469(1998)055<3417: EADINS $>2.0 . \mathrm{CO} ; 2$.

Cooper, W. A., and R. P. Lawson, 1984: Physical interpretation of results from the HIPLEX-1 experiment. J. Climate Appl. Meteor., 23, 523-540, https://doi.org/10.1175/1520-0450(1984) 023<0523:PIORFT $>2.0 . \mathrm{CO} ; 2$.

Cotton, W. R., G. J. Tripoli, R. M. Rauber, and E. A. Mulvihill, 1986: Numerical simulation of the effects of varying ice crystal nucleation rates and aggregation processes on orographic snowfall. J. Climate Appl. Meteor., 25, 1658-1680, https:// doi.org/10.1175/1520-0450(1986)025<1658:NSOTEO $>2.0 . C O ; 2$.

Dawe, J. T., and P. H. Austin, 2011a: The influence of the cloud shell on tracer budget measurements of LES cloud entrainment. J. Atmos. Sci., 68, 2909-2920, https://doi.org/ 10.1175/2011JAS3658.1.

, and — 2011b: Interpolation of LES cloud surfaces for use in direct calculations of entrainment and detrainment. Mon. Wea. Rev., 139, 444-456, https://doi.org/10.1175/ 2010MWR3473.1.

— , and — 2013: Direct entrainment and detrainment rate distributions of individual shallow cumulus clouds in an LES. Atmos. Chem. Phys., 13, 7795-7811, https://doi.org/10.5194/ acp-13-7795-2013.

de Rooy, W. C., and A. P. Siebesma, 2010: Analytical expressions for entrainment and detrainment in cumulus convection. Quart. J. Roy. Meteor. Soc., 136, 1216-1227, https://doi.org/10.1002/qj.640.

Feng, Z., S. Hagos, A. K. Rowe, C. D. Burleyson, M. N. Martini, and S. P. de Szoeke, 2015: Mechanisms of convective cloud organization by cold pools over tropical warm ocean during the AMIE/DYNAMO field campaign. J. Adv. Model. Earth Syst., 7, 357-381, https://doi.org/10.1002/2014MS000384.

Fritsch, J. M., and R. E. Carbone, 2004: Improving quantitative precipitation forecasts in the warm season: A USWRP research and development strategy. Bull. Amer. Meteor. Soc., 85, 955-965, https://doi.org/10.1175/BAMS-85-7-955.

Glenn, I. B., and S. K. Krueger, 2017: Connections matter: Updraft merging in organized tropical deep convection. Geophys. Res. Lett., 44, 7087-7094, https://doi.org/10.1002/2017GL074162.

Hallett, J., and S. C. Mossop, 1974: Production of secondary ice particles during the riming process. Nature, 249, 26-28, https:// doi.org/10.1038/249026a0.

Hannah, W. M., 2017: Entrainment versus dilution in tropical deep convection. J. Atmos. Sci., 74, 3725-3747, https://doi.org/ 10.1175/JAS-D-16-0169.1.

Hoffmann, F., Y. Noh, and S. Raasch, 2017: The route to raindrop formation in a shallow cumulus cloud simulated by a Lagrangian cloud model. J. Atmos. Sci., 74, 2125-2142, https://doi.org/ 10.1175/JAS-D-16-0220.1.

Jonas, P. R., and B. J. Mason, 1982: Entrainment and the droplet spectrum in cumulus clouds. Quart. J. Roy. Meteor. Soc., 108, 857-869, https://doi.org/10.1002/qj.49710845808.

Kessler, E., 1969: On the Distribution and Continuity of Water Substance in Atmospheric Circulations. Meteor. Monogr., No. 32, Amer. Meteor. Soc., 84 pp.

Klaassen, G. P., and T. L. Clark, 1985: Dynamics of the cloudenvironment interface and entrainment in small cumuli: Twodimensional simulations in the absence of ambient shear. J. Atmos. Sci., 42, 2621-2642, https://doi.org/10.1175/ 1520-0469(1985)042<2621:DOTCEI >2.0.CO;2.

Kogan, Y. L., and A. Shapiro, 1996: The simulation of a convective cloud in a 3D Model with explicit microphysics. Part II: Dynamical and microphysical aspects of cloud merger. J. Atmos. Sci., 53, 2525-2545, https://doi.org/10.1175/1520-0469(1996) 053<2525:TSOACC $>2.0$. CO 2 .

Krauss, T. W., A. A. Sinkevich, and A. S. Ghulam, 2012: Radar investigations of cloud merger. Russ. Meteor. Hydrol., 37, 604614, https://doi.org/10.3103/S106837391209004X

Laird, N. F., 2005: Humidity halos surrounding small cumulus clouds in a tropical environment. J. Atmos. Sci., 62, 3420-3425, https://doi.org/10.1175/JAS3538.1.

Lasher-Trapp, S. G., C. A. Knight, and J. M. Straka, 2001: Early radar echoes from ultragiant aerosol in a cumulus congestus: modeling and observations. J. Atmos. Sci., 58, 3545-3562, https:// doi.org/10.1175/1520-0469(2001)058<3545:EREFUA $>2.0 . C O ; 2$.

Leon, D. C., and Coauthors, 2016: The Convective Precipitation Experiment (COPE): Investigating the origins of heavy 
precipitation in the southwestern United Kingdom. Bull. Amer. Meteor. Soc., 97, 1003-1020, https://doi.org/10.1175/ BAMS-D-14-00157.1.

Lu, M.-L., J. Wang, R. C. Flagan, J. H. Seinfeld, A. Freedman, R. A. McClatchey, and H. H. Jonsson, 2003: Analysis of humidity halos around trade wind cumulus clouds. J. Atmos. Sci., 60, 1041-1059, https://doi.org/10.1175/1520-0469(2003)60<1041: AOHHAT $>2.0 . C O ; 2$.

Mansell, E. R., C. L. Ziegler, and E. C. Bruning, 2010: Simulated electrification of a small thunderstorm with two-moment bulk microphysics. J. Atmos. Sci., 67, 171-194, https://doi.org/ 10.1175/2009JAS2965.1.

Mapes, B., and R. Neale, 2011: Parameterizing convective organization to escape the entrainment dilemma. J. Adv. Model. Earth Syst., 3, M06004, https://doi.org/10.1029/2011MS000042.

Meyers, M. P., P. J. DeMott, and W. R. Cotton, 1992: New primary ice-nucleation parameterizations in an explicit cloud model. J. Appl. Meteor., 31, 708-721, https://doi.org/10.1175/15200450(1992)031<0708:NPINPI>2.0.CO;2.

Moser, D. H., and S. Lasher-Trapp, 2017: The influence of successive thermals on entrainment and dilution in a simulated cumulus congestus. J. Atmos. Sci., 74, 375-392, https://doi.org/ 10.1175/JAS-D-16-0144.1.

Mossop, S. C., and J. Hallett, 1974: Ice crystal concentration in cumulus clouds: influence of the drop spectrum. Science, 186, 632-634, https://doi.org/10.1126/science.186.4164.632.

Naumann, A. K., and A. Seifert, 2016: Recirculation and growth of raindrops in simulated shallow cumulus. J. Adv. Model. Earth Syst., 8, 520-537, https://doi.org/10.1002/2016MS000631.

Perry, K. D., and P. V. Hobbs, 1996: Influences of isolated cumulus clouds on the humidity of their surroundings. J. Atmos. Sci., 53, 159-174, https://doi.org/10.1175/1520-0469(1996)053<0159: IOICCO $>2.0 . \mathrm{CO} ; 2$.

Plummer, D. M., and Coauthors, 2018: Radar-derived structural and precipitation characteristics of ZDR columns within warm-season convection over the United Kingdom. J. Appl. Meteor. Climatol., https://doi.org/10.1175/JAMC-D-17-0134.1, in press.

Randall, D. A., and G. J. Huffman, 1982: Entrainment and detrainment in a simple cumulus cloud model. J. Atmos. Sci., 39, 2793-2806, https://doi.org/10.1175/1520-0469(1982)039<2793: EADIAS $>2.0 . \mathrm{CO} ; 2$.

Rauber, R. M., G. Zhao, L. Di Girolamo, and M. Colón-Robles, 2013: Aerosol size distribution, particle concentration, and optical property variability near Caribbean trade cumulus clouds: Isolating effects of vertical transport and cloud processing from humidification using aircraft measurements. J. Atmos. Sci., 70, 3063-3083, https://doi.org/10.1175/ JAS-D-12-0105.1.
Roesner, S., A. I. Flossmann, and H. R. Pruppacher, 1990: The effect on the evolution of the drop spectrum in clouds of the preconditioning of air by successive convective elements. Quart. J. Roy. Meteor. Soc., 116, 1389-1403, https://doi.org/ 10.1002/qj.49711649607.

Romps, D. M., and Z. Kuang, 2010: Nature versus nurture in shallow convection. J. Atmos. Sci., 67, 1655-1666, https:// doi.org/10.1175/2009JAS3307.1.

Siebesma, A. P., 1998: Shallow cumulus convection. Buoyant Convection in Geophysical Flows, Springer, 441-486.

Simpson, J., N. E. Westcott, R. J. Clerman, and R. A. Pielke, 1980: On cumulus mergers. Arch. Meteor. Geophys. Bioklimatol., 29A, 1-40, https://doi.org/10.1007/BF02247731.

Stalker, J. R., and K. R. Knupp, 2003: Cell merger potential in multicell thunderstorms of weakly sheared environments: Cell separation distance versus planetary boundary layer depth. Mon. Wea. Rev., 131, 1678-1695, https://doi.org/10.1175// 2556.1.

Stommel, H., 1947: Entrainment of air into a cumulus cloud. J. Meteor., 4, 91-94, https://doi.org/10.1175/1520-0469(1947) 004<0091:EOAIAC $>2.0 . \mathrm{CO} ; 2$.

Tao, W., and J. Simpson, 1989: A further study of cumulus interactions and mergers: Three-dimensional simulations with trajectory analyses. J. Atmos. Sci., 46, 2974-3004, https:/ doi.org/10.1175/1520-0469(1989)046<2974:AFSOCI>2.0.CO;2.

Taylor, J. W., and Coauthors, 2016: Observations of cloud microphysics and ice formation during COPE. Atmos. Chem. Phys., 16, 799-826, https://doi.org/10.5194/acp-16-799-2016.

Turpeinen, O., and M. K. Yau, 1981: Comparisons of results from a three-dimensional cloud model with statistics of radar echoes on day 261 of GATE. Mon. Wea. Rev., 109, 1495-1511, https:// doi.org/10.1175/1520-0493(1981)109<1495:CORFAT >2.0.CO;2.

Twohy, C. H., J. A. Coakley, and W. R. Tahnk, 2009: Effect of changes in relative humidity on aerosol scattering near clouds. J. Geophys. Res., 114, D05205, https://doi.org/10.1029/ 2008JD010991.

Wang, Y., L. Zhou, and K. Hamilton, 2007: Effect of convective entrainment/detrainment on the simulation of the tropical precipitation diurnal cycle. Mon. Wea. Rev., 135, 567-585, https://doi.org/10.1175/MWR3308.1.

Warner, J., 1955: The water content of cumuliform cloud. Tellus, 7, 449-457, https://doi.org/10.3402/tellusa.v7i4.8917.

Yeo, K., and D. M. Romps, 2013: Measurement of convective entrainment using Lagrangian particles. J. Atmos. Sci., 70, 266277, https://doi.org/10.1175/JAS-D-12-0144.1.

Ziegler, C. L., 1985: Retrieval of thermal and microphysical variables in observed convective storms. Part 1: Model development and preliminary testing. J. Atmos. Sci., 42, 1487-1509, https://doi.org/ 10.1175/1520-0469(1985)042<1487:ROTAMV>2.0.CO;2. 